\title{
The making of meaning through dyadic haptic affective touch
}

\author{
Sara Price \\ UCL Knowledge Lab, University College London, London, UK, sara.price@ucl.ac.uk \\ Nadia Bianchi-Berthouze \\ UCLIC, University College London, City, London, nadia.berthouze@ucl.ac.uk \\ Carey Jewitt \\ UCL Knowledge Lab, University College London, London, UK, c.jewitt@ucl.ac.uk \\ Nikoleta Yiannoutsou \\ European Commission, Joint Research Centre, Spain nyiannoutsou@gmail.com \\ Katerina Fotopoulou \\ Psychoanalysis Unit, University College London, London, UK, a.fotopoulou@ucl.ac.uk \\ Svetlana Dajic \\ UCLIC, University College London, City, London, svetlanadjajic@gmail.com \\ Juspreet Virdee \\ UCLIC, University College London, City, London, juspreet.virdee.18@alumni.ucl.ac.uk \\ Yixin Zhao \\ UCLIC, University College London, City, London, yixin.zhao.18@alumni.ucl.ac.uk \\ Douglas Atkinson \\ UCL Knowledge Lab, University College London, London, UK, douglas.atkinson.17@ucl.ac.uk \\ Frederik Brudy \\ UCLIC, University College London, City, London, f.brudy@cs.ucl.ac.uk
}

\begin{abstract}
Despite the importance of touch in human-human relations, research in affective tactile practices is in its infancy, lacking in-depth understanding needed to inform the design of remote digital touch communication. This paper reports two qualitative studies that explore tactile affective communication in specific social contexts, and the bi-directional creation, sending and interpretation of digital touch messages using a purposebuilt research tool, the Tactile Emoticon. The system comprises a pair of remotely connected mitts which enable users in different locations to communicate through tactile messages, by orchestrating duration and level of three haptic sensations: vibration, pressure and temperature. Qualitative analysis shows the nuanced ways in which 68 participants configured these elements to make meaning from touch messages they sent and received. It points to the affect and emotion of touch, its sensoriality and ambiguity, the significance of context, social norms and expectations of touch participants. Findings suggest key design considerations for digital touch communication, where the emphasis shifts from generating 'recognizable touches' to tools that allow people to shape their touches and establish common understanding about their meaning.
\end{abstract}

\section{CCS CONCEPTS}

Human-centered computing Human computer interaction (HCI); Haptic devices; User studies 


\section{KEYWORDS}

Digital touch; affective communication; remote touch

\section{Introduction}

Advances in haptic technologies enable new ways to remotely communicate a feeling of touch [4]. Despite being unable to fully replicate the cutaneous and kinaesthetic properties of physical touch $[19,69]$, touch technologies have the potential to bring sensory benefits to distant communication [18,19]. Touch, being a complex but critical sense in human interaction and communication, presents an ongoing challenge for technological design and development. Embedding digital touch into social sensory contexts of established touch communication is complex and raises key design issues for effective mediated touch communication. This paper reports two studies using a purpose-built research tool, the Tactile Emoticon (TE), that allows two people to send and receive tactile messages over a distance. It uses commonly implemented haptic sensations of vibration, pressure and temperature that users can orchestrate in terms of duration and intensity. The system is not the focus of the studies; rather it is used as a research tool to gain in-depth understanding of how people use these haptic sensations for meaningful affective communication and the implications of this for haptic design. To better understand touch practices, the system was used separately from other media in the studies. However, participants were free to consider the system in a broader media communication setting, and we envisage the study findings may transfer to situations where digital touch is used in tandem with other communication channels (e.g., video conferencing, VR).

Touch, being central to human experience [7] and communication [23], plays a vital role in forming and maintaining intimate social bonds and is beneficial for relational, psychological, and physiological well-being [33]. Meaning making through touch (the process of how people make sense of touch in communicative contexts) is constructed in interaction with others in particular cultural contexts, giving rise, not only to sensory forms of communication, but also etiquettes around which touch is allowed: where, when, how and by whom. In other words, touch is socially grounded [55], and closely connected to our emotions [11], creating a complex design space for touch technology to mediate affective experiences. While the action of touching another is typically straightforward, many factors influence the message being communicated. Social touch is more than stimulation of the skin. It involves other (verbal, visual, proxemic) cues that together with context and prevailing social norms define the meaning of a touch. For example, the firmness with which a person cups another's hand can be supportive or aggressive; the perceived bodily warmth (or lack of), the amount of movement or stillness in the touch, the body part used to touch or be touched, all demonstrate the nuanced space of touch communication. This research moves beyond the more general parameters of 'connectedness' or 'pleasantness' to better understand the mapping between synthetic tactile actuation methods and emotional communication. It thus explores the localized and changing character of touch through the intensity of kinematic qualities (movement and speed, direction, pressure), the shape of the hand, and types of touch (e.g. tap vs pinch), where the movement of the arm/hand is visible before touch is applied and touch gestures are all considerations in the construction of touch messages.

Alongside the social complexity of touch, current technical limitations restrict the kinds of touch experiences that can be implemented, with digital touch devices typically relying on vibration, pressure or temperature. While synthetic touch cues such as these [19,55] have been shown to be successful in creating meaningful tactile experiences (e.g. a vibration on the lower arm [38]), and triggering emotions akin to those attached to existing physical touch practices [9] (e.g. hand holding), few studies to date have explored these tactile actuation methods in one system. This research responds to this gap by engaging with this wider complement of critical actuation methods [19,53] and approaching touch communication and interpretation from a social perspective (i.e. engaging with the role of social norms, agency, gender, context, how and when people touch in social relationships) as important for informing future technical development.

A qualitative research design was used in two studies to better understand ways in which haptic technologies can enable meaningful touch communication, and to inform design. Study 1 explored how tactile affective communication takes place between two people in a physical space and the implications for digital touch communication. Study 2 explored the bi-directional creation/sending and receiving/interpretation of digitally 
mediated touch messages. This paper is the first to contribute a broader understanding of digital touch communication practices by exploring a variety of simulated social contexts (friends, family, romantic or work relationships), and a diverse set of contextually-related emotional scenarios (rather than emotions per se). The studies provide in-depth understanding of the experiential factors that contribute to creating and attaching meaning to touch communication in the physical and digital space, in particular: participant descriptions of the sensorial and physical sensations received and sent through the different touch properties (temperature, pressure and vibration); the differential use of these properties to craft and configure touch messages to convey affective forms of communication and the importance of perceiving recipient reaction, for a close-coupled interactive loop; the value of ambiguity and related importance of context; and the design implications for digital touch communication

\section{Background}

\subsection{Social aspects of touch communication}

Touch plays a central role in the construction of our experiences and understanding of the world, ourselves and one another. It is significant for developing and maintaining personal relationships, from ritualized greetings, to communicating emotion or intimacy [49]. Touch is central to our development [20], an effective means of influencing attitudes, creating bonds between people, places or objects [45], and improving information flow and compliance [20]. While it may not be much spoken about, touch provides significant information and experience of the world: "Just as we 'do things with words' so, too, we act through touches" [17]. Touch is considered to be the clearest of all non-verbal cues [60] and able to communicate a range of emotions effectively via specific touch actions [32,33]. Indeed, knowing how to infer meaning from touch is considered the very basis of social being [16]. More generally, increased interpersonal touch in relationships is associated with benefits to one's relational, psychological, and physiological well-being [40], for instance, touch can enhance a positive mood and lessen a negative one [14] and reduce blood pressure and resting heart rate [48].

The type and strength of a relationship between people affects how much and where on the body people think it is appropriate to touch [47]. Touch is particularly significant in close or intimate relationships as it is correlated with overall relationship satisfaction [27] and shown to create and strengthen bonds between couples, with a lack of touch having negative connotations [23]. Touch can have both positive and negative effects on work-based relationships [64]; however, when used appropriately it has potential in regulating workplace relationships [22].

The opportunities for such important tactile exchanges are decreasing. New social arrangements, such as migration, increased work mobility, and changing norms of family-life, have led to partners, friends and families living apart, often separated by long distances and periods of time. Recent touch restrictions in response to the COVID-19 pandemic have exacerbated a sense of disappearing touch even when people are in close proximity. This loss of social touch is a challenge for interpersonal interaction and communication. While people use a range of communicative technologies (e.g. video calling) to connect with friends, family, and partners, these are typically used for transactional communication [31]. These technologies lack the physicality of touch [30], which in the context of close relationships is seen as problematic - "the voice is not enough. The relationship is so physical and visual" [52]. Digital touch devices are increasingly being designed and marketed to mitigate this lack.

\subsection{How is affective touch created and interpreted?}

Touch has been identified as an important non-verbal channel to convey affective messages. In [33] strangers were asked to decode the emotional intent of a touch message they received when physically touched by another person they could not see or to talk to, despite standing close to each other. Emotions including anger, fear, disgust, love, gratitude, and sympathy were recognized with accuracy rates similar to, if not higher than, those observed for other non-verbal communication channels. The study identified strong associations between emotions and specific touch gestures, and between emotions and the kinematics of the gestures 
(pressure intensity, speed, acceleration and duration). The interpretation of the emotional message was also shaped by the region of the body being touched. However, limited regions of the body (e.g. arm vs head vs chest) were considered. In a similar study in the context of human-robot interaction [1] participants read scenarios and then used touch to express the described emotion to a Nao robot.

The relationship between touch and emotions was also investigated using mid-air haptics by [53], asking a group of participants to represent emotions evoked by a set of eliciting pictures through controlling air sent to specific parts of the hand, and then asking another group of participants to interpret the air-based haptic messages. Although the study was not in the context of human-human interaction, a second group of participants were able to identify the patterns used to create the mapping, showing the non-arbitrary link between emotion and touch patterns. Interestingly, this study showed how participants associated different areas of the hand with different levels of valence and arousal. This association was based on the level of pleasantness of the air sensation and the amount of perceived control on the hand area (e.g. being able to easily remove the thumbs vs the palm from the air), and the direction of the movement. A sense of intimacy was also linked to how much of the hand, and how close to the central region of the hand, a person was touched.

This body of work has led to the study of emotional touch in computing. Based on the same touch gestures and kinematics mentioned above, affective computing researchers have demonstrated the feasibility of creating software that can automatically recognize people's emotional states from the way they touch a display or keyboard or robot (for a review see [24]). For example, [2] showed a machine learning model could discriminate between seven emotional states conveyed through hand shaking simulated by participants moving a joystick. Recognition was well above chance level (36\%), and similar to recognition performance of human participants when asked to label the perceived joystick movement. In human-human hand shaking interaction the human recognition rate was 50\%. [2]. Similarly, the work in [24] shows that in an emotionally charged ecological setting (touch-screen computer games), even if not a human-human communication one, tactile kinematics allow users to automatically discriminate between four players' emotional states with a level of reliability seen for other modalities ( $80 \%)$ [44]. In both studies, a combination of statistical measures of intensity, direction, acceleration, duration and velocity of touch patterns emerge again as critical in these machine learning-based inference models. Given the identified affective kinematic patterns, it can be argued that there is a clear parallel between how we express emotion through touch gestures and how we express emotion through our body movement (e.g. for literature on affective body expressions see $[8,26,44,46,54]$. These findings suggest that a language of affective touch exists in stereotypical or emotionally charged situations, that is grounded in its dynamics, and that technology for distance-relationships could build on such dynamics to deliver affective digital touch.

However, this work is limited to interpreting tactile messages often created outside of a context and fails to provide in-depth understanding ofd the complexity of how affective touch is created and decoded, and of the experiential and contextual factors shaping those processes. Earlier work by [28] argues for the importance of understanding such language rather than considering that it is the same as its physical counterpart. Taking a tactile semiotic approach, their work investigated if people associated emotions to tactile experiences of texture. Their work showed how people tended to agree on the emotion associated with touch experiences of more natural textures (e.g., trees) but agreement decreased with less natural everyday material. Other studies [57] have explored how digital sensations to a person's arm changed the person's perception of textile qualities while they observed someone else handling the textile. In their work, warm sensations sent to the hand while looking at the same textile led to an increased rating in softness of that material in comparison to cold sensations. Vibration feedback led to a perception of roughness of the textile. The emotional experience was enhanced by tactile gestures used by the person handling the textile. This suggests that digital sensations together with tactile kinematics contribute to creating emotional experiences. According to [18], it is critical that affective remote tactile communication should not simply rely on symbolic communication but rather taps into the immediacy and experiential nature of the human affective systems. For example, according to [28] using a vest equipped with multiple vibrotactile actuators, body location led to reactions similar to those observed in the case of physical touch, although this was not gender related. Yet studies reported in [21,34,71] seem to suggest the opposite, i.e. similarity in responses between physical and digital touch were related to 
dyad's gender. As such these initial findings call for more in-depth studies to better understand digital touch processes and factors shaping and affecting their uses and practices.

\subsection{Touch technologies for remote communication}

Recent years have witnessed fast growing innovation in haptic technology aiming to create richer, more effective and organic tactile affective feedback. For example, a study used iterative rapid prototyping to explore a variety of wearable haptic design solutions to simulate tapping and squeezing tactile patterns [3]. These two gestures were selected as they emulate attention-grabbing practices, and their kinematic variations were created to modulate their affective meaning. Results confirm other studies showing that people show high agreement in assigning meaning to specific tactile patterns and their kinematics. Building on this work, [67] explored new technical solutions to enrich the set of tactile gestures that are possible and to produce more gradable temporal variations of such gestures that could be easily felt in specific locations of the skin. More recently, [30] has proposed Springlets, an expressive, non-vibrating mechanotactile skin interface that can stretch the skin. This solution extends the vocabulary of affective gestures by simulating pinching, directional stretching, pressing, pulling, dragging and expanding in various directions. Other work has focused on reducing the bulkiness of these solutions to integrate them into small accessories such as watches and rings (e.g., SkingDragDisplay [39] and TactoRing [62]). Building on this work, [51] provide suggestions on how to enable more complex patterns, reduce delay, cooling and noise issues and enable integration into textiles. While these technical advances open the possibility for a rich set of tactile sensations, their evaluation to date has focused solely on assessing their ability to express stereotypical and predefined affective expressions that could be correctly recognized or agreed upon. What is missing, and what this paper offers, is a more in-depth investigation of how digital affective tactile communication occurs, its form and the factors that may affect it.

Relevant to our research question is the growing number of 'mediated social touch' prototypes that are specifically designed to explore remote communication. The majority are built for playful (e.g. tickling) or symbolic purposes (e.g. presence), with some for affection and greeting [19,29,30,35-37,74]. These prototypes have predominantly taken more traditional approaches, using force and vibration, either alone or combined as actuation modalities, with some use of pressure and temperature. Typically, they enable touch on the hand, with some focusing on other parts of the body (e.g. foot and trunk). For instance, VibroBod [15] utilizes finger position and force to send a set of emotional states in the form of vibration patterns. A stroking device [17] enables the feel of a partner's stroke over distance, aiming to support the expression of love, joy or even anger. Other examples of these technologies aim to support touch communication employing different combinations of vibration, pressure and heat, addressing not only the hand (like the vibrating rings [78], HotHands and HotMits [25] or the Flex-N-Feel gloves [65], or SansTouch [80]) but also the feet (slippers [10]), the cheek (POKE [56]) or the whole body (Huggy Pajama [73]) or any part of the body (SwarmHaptic [43]).

The survey presented in [29] shows that these initial studies on remote digital touch are explorative and mainly focused on showing how remote touch enhances the sense of presence and awareness of the other and how people can build or use affective tactile symbols. Some of this work has also shown that tactile feedback can be used to support other forms of multimedia interaction (e.g., phone conversation) by providing a means for easier turn-taking and to help emphasise messages. The work in [66] highlights the need to systematically investigate the various factors and key dimensions that may affect remote touch. Their study shows the importance of dyad relationships, the type of contexts as well as level of awareness of the presence of the other (e.g. the perceived distance between them). Unfortunately, only romantic partners and strangers were investigated with the latter less capable of discriminating between emotions. Contexts (social vs functional) appeared to have an impact; comparison of a handstroke and pingpong touch showed that the emotion conveyed by a handstroke was easier to recognize [56]. However, the work was mainly lab-based, with a four emotion simulation/recognition task using a neutral and simplistic device (a knob). The authors stressed the need for more ecological methods and exploration across different device types and across the above dimensions. Using a more ecological setting and a short longitudinal study, the work reported in [56] with POKE found that romantic couples build their own tactile language over a week of use, although the design 
was limited in terms of modalities and mainly used in conjunction with phone calls. Another study [30] highlights that this body of work is based on the assumption that digital touch is the same as physical touch.

However, such an assumption needs to be investigated. This is the case even for very recent work such as the SansTouch [80] wearable used to investigate digital tactile greetings in working co-situated encounters during Covid-19. This work focusses on assessing the acceptability, usability and enjoyment of the device. For most devices, gestures are often fully predefined (e.g., hand shaking vs waving) leaving little space to investigate how the basic building block of affective touch (e.g., skin sensations) translates to use in digital contexts or whether affective digital touch practices differ from affective physical touch ones. Other work $[21,34,39,51,62]$ has used prototypes to stimulate discussion about tactile communication in scenario-based focus groups and interviews, suggesting the use of vibrotactile stimulation to communicate emotion, thermal feedback to notify someone of something, and a squeeze for a more varied range of scenarios [70]. Other work has explored affective touch through technology where touch is created in response to other stimuli, such as being elicited through galvanic skin response [77] or in wrist-based smart devices [75] to examine self-awareness and interpretation of emotion. Here the focus is on capturing and communicating users' emotions to support self-understanding rather than bidirectional human-human communication. Little work has looked at the real-time mapping of digital tactile sensations to emotion or deeper exploration of meaningful communication through digital touch, leading to development of meaningful devices.

While the literature above demonstrates the power of touch as an affective communication channel, studies mainly focus on understanding how touch is used to express and decode specific, often out of context, emotions. As such most of these studies explore the possibility of conveying and interpreting stereotypical affective messages or gestures. However, little is still known about the dynamics and factors that affect the creation and interpretation of ecological tactile exchanges [65].

This paper contributes to reducing this knowledge gap with an in-depth understanding of such processes situated in specific contexts and semi-ecological settings through qualitative studies rather than controlled recognition studies. Rather than asking participants to enact specific emotional states, participants are proposed an emotional context via a scenario within which they are asked to communicate through touch. Crucially, the research reported in this paper demonstrates the value of using early-stage prototypes as exploratory research tools to evoke conversation rooted in a tangible experience, rather than an abstract idea of mediated touch. By combining the haptic sensations of heat, vibration and pressure for the purpose of communicating emotion through touch (rather than exploring them separately) the paper extends work on their use. It takes context of communication into account and examines the bi-directional nature of touch communication.

\section{Research design}

Gaining in-depth understanding of the mapping between specific synthetic tactile actuation methods and emotion that moves beyond general notions of 'connectedness' or 'pleasantness' is challenging. In order to do this, we designed a research-informed haptic system, the Tactile Emoticon (TE), to be used as a research tool to elicit exploration, implementation and conversation around bi-directional touch communication. This system combined the use of temperature, pressure and vibration, and was designed to be flexibly used by participants to create their own touch messages. Two user studies explored how pairs of participants used the system, specifically focusing on their use of the haptic sensations for meaningful affective communication. The system helped participants to externalize tactile communication processes and their meaning, and to bring an initial understanding of how touch-based technology might enable tactile affective communication at a distance. Since mediated touch is inherently shaped by context [18] the studies were designed around particular social relationships between participants and related communicative situations. Participant pairs comprised friends, family, romantic or work relationships, from one month to 4.5 years duration. We do not compare these different participant groups (as in [66]); rather we used them to generate data on different relationship contexts and types and levels of touch, providing a deeper and broader understanding of digital touch by leveraging different scenarios of communication. In each study three to four scenarios (their naming 
shaped by the communicational contexts) were designed around emotions to elicit affective support in different communicative contexts where affective touch is considered (within the literature) to be beneficial, including loneliness, excitement, distress, sadness, anger and rejection. Scenarios were short textual descriptions to promote a sense of realism for communication and reflection, by prompting participants to imagine a concrete situation in which the target emotion might be felt.

Study 1 focused on gaining an initial understanding of how people's tactile communication takes place and the factors that may affect it in the context of friends, romantic partners and work colleagues. The TE with its haptic sensations of pressure and temperature served as a way to enhance people's awareness of their tactile practices as well as of the tactile sensations through which meaning is created and interpreted. Study 2 aimed to enrich this understanding by exploring the use of all three haptic sensations (pressure, temperature and vibration), with a focus on examining the process of how participants compose, send and interpret remote digital tactile messages between friends, family and romantic partners.

The research received approval from UCL ethics board (REC 786), all participants received clear instructions on how to use the system and how to modify intensity, duration and frequency of the dimensions (temperature, pressure, vibration) to ensure its safe use and were encouraged to withdraw their hand at any point if they felt uncomfortable or unsure.

\section{The Tactile Emoticon system: a research tool}

The TE system included three haptic sensations, vibration, pressure and temperature, chosen based on affective touch literature as the main emotion discriminative features, being strongly related to skin receptors, and given the evidence for strong links between thermal skin changes and emotion [59]. These are also common digitally implementable modalities that have not been explored collectively in a context where users can design touch by integrating these tactile sensations. The development ideation phase led to a variety of ideas of how these tactile sensations could be packaged into an interactive system that allows two people to communicate via touch over a distance. In this section, we describe the final design of a touch-based system for distance tactile communication followed by a description of how it works (see appendix for details on design process).

\subsection{Tactile Emoticon system}

The TE system comprises a pair of linked purpose-built interactive devices that enable two people to communicate remotely through touch. A hand mould (mitt) was selected given its technical feasibility, and capacity to offer: 1) the best potential in terms of communication; 2) originality and playfulness; 3) social suitability for exploring tactile sensations, since hand-holding is not generally considered too intimate and is perceived as emotionally supportive. Each device is shaped like a mitten, mounted on to an acrylic box, which houses buttons and sensors controlling the type of tactile feedback to send to the other mitten (Figure 1). Each mitt is made from neoprene (1.5mm thickness), providing a breathable material that reduces moisture and increases softness and invites a person to slide their hand inside (a in Figure 1). The soft fabric absorbs vibrations, so the vibrations stayed localised to the actuators' position (b in Figure 1), and the texture has a soft dry, neutral feeling. LED illuminated control dials were added for temperature, pressure and vibration to gradate the tactile sensations and give a stronger sense of user control and sensitivity to the other (f-k in Figure 1). The pressure module (a in Figure 1) was designed to give a sensation of being gently held or encased below (on the palm) and above (on the back of the hand). The touch sensors comprised large rectangular pieces of force-resistive fabric to enable large pressure sensitive areas located vertically along the bottom of the mitt (d in Figure 1). Each pressure sensitive strip controlled one to two vibration motors (b in Figure 1). We opted for a vertical arrangement so that a stroking movement could be triggered. A temperature module was placed at the bottom of the mitt which could be heated up or cooled down (c in Figure 1). Using the mode controls on the left side of the device (i-k in Figure 1), users could activate each of three types of tactile feedback modules: vibration, temperature and pressure. Additionally, there was a control where sensations could be felt locally. 

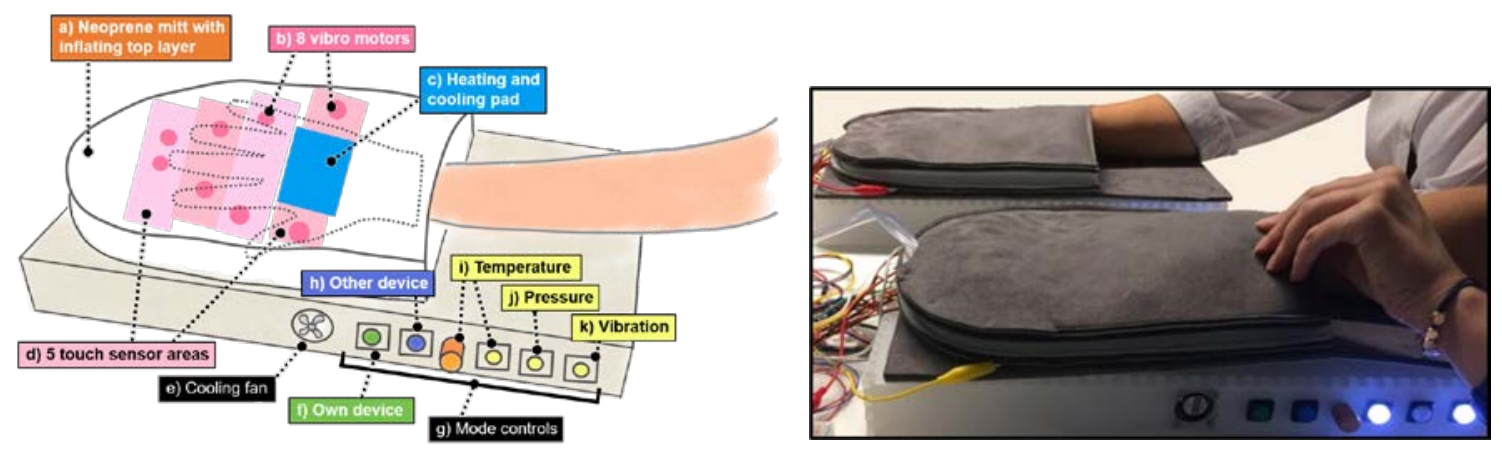

Figure 1: Tactile Emoticon prototype. Prototype design (left); A participant exploring mittens that act as both Receiver and Sender (right).

\subsection{Tactile Emoticon use guide}

We use the terms Sender and Receiver to describe the conceptual roles the devices are taking on. However, both devices are equivalent and can both send and receive touch. We use this terminology here to describe the systems functionality from a single user's perspective. Two buttons on the side turn the sending of signals to the other (remote) device on/off (h in Figure 1) and activate whether interactions can be felt locally ("feel own mode"; f in Figure 1) (https://youtu.be/hwr4PTvTuAA).

\subsubsection{General system overview}

Configuration in one device (Sender) results in corresponding sensations being felt in the other (Receiver). On the Sender side Vibration, Temperature, and Pressure modules can be activated independently from each other. The Vibration module replays touch pressure sensed on the bottom of the Sender device in the form of vibrations on the Receiver (b \& d in Figure 1). Temperature allows the device to cool down or heat up a $5 \times 5 \mathrm{~cm}$ area in the bottom of the mitten controlled by a rotary dial (c \& i in Figure 1). Pressure gently inflates the top of the mitten to apply pressure on receiving user's hand over the course of 60 seconds (a \& j in Figure 1). Sending sensations to the other device can be turned off entirely (by toggling off "other device"; $h$ in Figure 1). Receiving sensations cannot be disabled beyond withdrawing the hand from the mitten. In addition to sending sensations to the other device, users can choose to feel the feedback they are sending on their own device ("own device"; $\mathrm{f}$ in Figure 1). This feature aimed to simulate the fact that touch is reciprocal and thus touching also means being touched. Either hand could be placed in the device, with no difference in how the system functioned beyond the placement of the actuators in relation to the hands. The components in each device are controlled by an Arduino Mega, with a wired connection between the devices for sending control messages.

Here we describe each of the modules' functioning in detail.

\subsubsection{Vibration (b \& d in Figure 1)}

The bottom-half of the mitten contains five touch sensitive areas made by layering the neoprene with conductive thread and piezo-resistive EeonTex Pressure Sensing Fabric ( $d$ in Figure 1). To communicate the sensed touch between devices, we map the pressure sensors from the Sender device to the corresponding vibration motors on the Receiver device. Eight vibration motors are used, the larger three areas at the top are actuated by two motors each, to allow vibration to be felt across the entire width (b in Figure 1). The base of each mitten is composed of three layers of neoprene fabric. The vibration motors are mounted in precisely sized cut outs in a central layer of neoprene, which is encased in an upper and lower layer of the same fabric. The fabric layers are glued together using latex based rubber adhesive, but the vibration motors are not fixed to any surface, rather they are held in place by their encapsulation in the fabric layers. We use VPM2 Linear Resonant Actuators (LRAs) for the vibration module, with a resonant frequency of approximately $150-250 \mathrm{~Hz}$ and an operating voltage of 2.5- 3.6V . By using LRAs we can adjust the vibration amplitude, allowing us to produce a range of haptic waveforms. By turning the vibration of individual motors on/off and by 
controlling the intensity we can create a pattern in an individual motor (e.g., a pulsing or caressing pattern). The level of resistance on the sensor is mapped to the amplitude of the vibration. Duration of resistance on the sending device is mapped to the duration of the vibration on the receiving device. In other words, vibration amplitude and duration directly map to how hard and long pressure is applied by the hand to each sensor area in the mitten. With a toggle button the vibration module can be switched on/off. When off, the pressure sensing module is deactivated, therefore not sending any touch actuation to the Receiver. When the 'feel own' functionality is activated the Sender device actuates the vibration motors locally as well.

\subsubsection{Temperature ( $\mathrm{c}$ in Figure 1 )}

In the bottom of the base the $5 \times 5 \mathrm{~cm}$ temperature module is located. It comprises a heating pad (a polyimide film containing a polyester filament and Micro metal conductive fibre) layered on top of a cooling element (Neuftech TEC1-12706 Peltier Element), covered by a thin layer of fabric. The temperature module can be turned on/off with a toggle button (i in Figure 1). The setting is controlled with a rotary potentiometer on the side: a counter-clockwise turn controls the cooling unit, a clockwise turn controls the heating unit. Both the heating pad and the Peltier element can only be turned on or off but lack nuanced temperature control. We therefore control the overall temperature by changing the frequency and duration of the on/off cycle. For that, we map the potentiometer's reading to a range $x$ of $-15-+15$. If the value is $x<-1$ the cooling mode is activated, for $x>1$ the heating mode is activated. Between this the temperature output is set to neutral (neither heating nor cooling), accounting for noise in the analogue signal of the potentiometer. Through pilot testing we found $x^{*} 350$ milliseconds to be a good oscillation interval for the on/off cycle. For example, with the heating unit: when set to $50 \%$ the heating element is active for 2.6 seconds, followed by 2.6 seconds of inactiveness. At $75 \%$, the heating elements heats for 3.9 seconds, followed by 3.9 seconds inactiveness. This pattern repeats until the dial is changed or turned to neutral. In the neutral position the heating element is switched off. Similarly, when the dial is turned to 'cooling', the cooling element is controlled. The resulting temperature is an integral of past heating, cooling, and time off (and ambient temperature). Through this on/off cycle, the device operates within NASA's safe temperature limits: $0^{\circ} \mathrm{C}-50^{\circ} \mathrm{C}$ [76]. Practically the maximum temperature stayed below $50^{\circ} \mathrm{C}$ and reaches this only after $\sim 4-5$ minutes at $100 \%$. The temperature module was covered by fabric, preventing direct touch and harm; users could remove their hand easily at any time if feeling uncomfortable. We do not claim to allow for precise temperature control, but rather to provide an interface that can be used to communicate changes in temperature and a general feeling of warm or cold.

\subsubsection{Pressure $(j$ in Figure 1$)$}

The top-half of the mitten housed a 12-inch latex balloon between two layers of neoprene for creating a pressure sensation. Two pumps inflated and deflated the balloon, using pneumatic electric solenoid valves to seal in the air. Pressure was time-dependent: when a user chose to turn pressure on ( $\mathrm{j}$ in Figure 1), the balloon inflated, slowly increasing the pressure, reaching maximum inflation and thus pressure after 60 seconds. This duration was determined after pilot study findings to allow for a comfortable amount of pressure while still allowing receiving users to move their hand. After inflation finished, the pressure in the balloon was held until the sending user chose to deflate it by turning the pressure function off. With 'feel own' activated, the total of inflation and deflation sent and received is totalled up, resulting in the target inflation level.

\section{Study 1: Understanding TE inspired affective communication}

Study 1 was designed to explore and understand how affective tactile communication takes place, specifically around the multimodal characteristics of tactile communicative gestures, the role of context in shaping tactile communication, and the role of pressure and temperature in communicating affective sentiment. The TE is used to increase study participants' awareness of physical and digital affective tactile communication leading to richer insights.

\subsection{Participants}

Twenty-eight pairs of participants were recruited from the University Subject Pool (compensated according to the standard university ethics fee): 
Friendship (F): 9 pairs: 4 pairs of female friends, 2 pairs of male friends, and 3 pairs of female-male friends, aged from 19-30 years, with a duration of friendship of 1-12 months.

Romantic partnership (R): 9 couples (8 males and 10 females), 6 opposite-sex couples and 3 same-sex couples, aged from 18-32 years. Length of relationship from 1 month to 4.5 years.

Working relationships (W): 10 student pairs (8 males and 12 females) focusing on classmate-classmate and teacher-student relationships. They were organized randomly in same sex pairs assuring that each member of the pair did not know each other to simulate distance co-worker scenarios.

\subsection{Procedure}

The interaction took place in a lab setting. Technical limitations meant that tactile feedback was limited to pressure and temperature. Due to limited length of the wires connecting the two devices, participant pairs used the system in the same room. However, participants were curtained off from each other with cardboard screens or a curtain to simulate the context of being apart. They followed explicit instructions not to comment to one another during the sending and receiving of the tactile messages. Two video cameras were set diagonally in front of the respective participants to capture the changes they made to the device when creating messages. Each session lasted 45 minutes to 1 hour, with researchers acting as facilitator observers. The study consisted of three phases:

Pre-interaction exploration involved describing the procedure and focus of study. Participants (in the same place/un-curtained) took turns to explore the TE, the pressure and temperature functionalities were explained, and any questions answered. This enabled participants to probe the device and understand how to modulate various modes to achieve different sensory effects.

The interaction phase (participants separated/curtained-off) involved message exchanges structured by the communication context, using the scenarios as a basis for each message to convey feelings of loneliness, distress, a feeling of being relaxed, ecstatic, fearful, longing, a feeling of peace, anger, comfort (Table 1). The scenarios and the communication context were adapted to each of the three contexts (R, F, W), with each participant being sender and then receiver. Receivers could respond by sending tactile messages to convey, for example, support, empathy, etc. After sending and receiving a message, participants were invited to describe the tactile messages they were sending or how the ones they received felt and demonstrate them on their hand.

\section{Table 1: Study 1 scenarios}

\begin{tabular}{|l|l|}
\hline Scenarios for friends \\
\hline Joy/Excitement & $\begin{array}{l}\text { Imagine a time when you receive good news (e.g. got accepted for a dream job, a } \\
\text { family member having a child, you won a prize) and want to share the excitement }\end{array}$ \\
\hline Loneliness & $\begin{array}{l}\text { Imagine a time when you were separated (by long-distance), you feel lonely and want } \\
\text { to feel connected. }\end{array}$ \\
\hline Distress & $\begin{array}{l}\text { Imagine a time when you feel distressed perhaps because of a bad mark at university, } \\
\text { or someone close to you was ill and needs support from you. }\end{array}$ \\
\hline Relaxed & $\begin{array}{l}\text { Imagine a time when you feel relaxed and are enjoying that moment (e.g. while } \\
\text { enjoying your time on a beach, or next to a fireplace) and want to share that feeling. }\end{array}$ \\
\hline Scenarios for romantic partners \\
\hline Ecstatic & $\begin{array}{l}\text { Imagine you have received very good news (e.g. a promotion). You want to share the } \\
\text { moment. }\end{array}$ \\
\hline Fear & $\begin{array}{l}\text { Imagine you are watching a scary movie at a moment of suspense. You fear something } \\
\text { is about to make you jump and you want to seek reassurance. }\end{array}$ \\
\hline Longing & $\begin{array}{l}\text { Imagine you are lying in bed after a demanding day at work and are longing for your } \\
\text { partners presence. }\end{array}$ \\
\hline
\end{tabular}




\begin{tabular}{|l|l|}
\hline Peace/Relaxed & $\begin{array}{l}\text { Imagine it is a sunny morning. You are sitting at your table, eating breakfast, and } \\
\text { watching the sun rise. You feel peaceful and relaxed, and you want to share this } \\
\text { moment. }\end{array}$ \\
\hline Scenarios for workers (education setting) \\
\hline Anger & $\begin{array}{l}\text { Imagine you are late with your work and your supervisor is angry. How would s/he } \\
\text { express her anger and how would you react? }\end{array}$ \\
\hline Comfort & $\begin{array}{l}\text { Imagine your classmate has received a very low mark and is feeling down. You want } \\
\text { to comfort her/him. Now imagine you are the one being comforted and how you would } \\
\text { react. }\end{array}$ \\
\hline Happiness & $\begin{array}{l}\text { Imagine your classmate has received a very high mark and you want to show how } \\
\text { happy you are for her/him. Now imagine you are the one being congratulated and how } \\
\text { you would react. }\end{array}$ \\
\hline
\end{tabular}

Post interaction semi-structured interviews aimed to better understand participants' experiences of the tactile messaging experience. Across the interviews, participants' gesture and touch, together with their talk, demonstrated and elaborated on these messages and on their interaction with the device. This made visible aspects of touch not apparent from observation of interaction with the device, and triggered participants' thoughts about design requirements for the device/system through their re-enactments. Questions were also asked around the overall experience with the system to understand what qualities of touch were lost or gained, notable experiences, similarities and differences with physical exchanges, meanings conveyed and perceived, and potential use of future systems to communicate digitally through touch.

A follow up phase took place in the context of work relationship participants. These participants had more difficulties in considering affective or social touch as an important communication channel per se in the context of work. Hence, 11 participants agreed to come back (individually) one week later to discuss the same scenario. The week interval aimed to make them be more aware of touch instances in their work context. A semi-structure interview drew on the same scenarios and participant were asked to discuss touch gestures and enact the gestures on their own hands or use the researcher hand.

\subsection{Data analysis}

Thematic analysis of the data followed the six phases proposed by Braun and Clarke [5]: familiarization with data through video watching, transcribing; generating initial codes, interesting and meaningful to the study aims; collating codes to generate themes; reviewing themes; defining and naming themes; providing evidence in relation to themes. Interview recordings were qualitatively analysed using Nvivo 12, and key relevant moments of touch interaction were identified from the video recordings to elaborate on the thematic analysis. Video data of participant demonstrations via gesture to express a specific emotional state were also annotated. Participants are identified by their relationship contexts (R, F, W \#) followed by the participant identifier (e.g. $\mathrm{F} 1$ for participant 1 in the friend context). We also indicate the role of receiver or sender if appropriate. As the study was designed to immerse people in situations to elicit tactile communication flow in addition to participants' comments on creating and interpreting emotional messages, some of the quotes also express their thoughts on the sensation and the situation independent of their specific role in that moment.

\subsection{Findings and discussion}

Four key themes emerged through the analysis: contextualized touch interpretation; the use of the hand as a complex 'touch' space; the physicality and agency of touch and its sense of connectedness; and the role of the system in conveying affect and emotion.

\subsubsection{Contextualized touch interpretation}

Participants found interpreting (and sending) affective support through touch to be subtle and highly ambiguous. However, user interpretations were generally compatible in terms of the affect sentiment of the tactile message (e.g. reassuring, soothing, comforting, exciting). Communicative context was crucial to this: typified by this comment in the sad and lonely scenario "If I didn't know the context, I wouldn't have felt 
anything at all. Now, I think this is supposed to be cold and knowing that she wants to send loneliness..." (R7-receiver). Participants tended to infer what the sender would want to convey based on their knowledge of the scenario, and created or interpreted touch characteristics accordingly. For example, most participants in the sadness scenario interpreted the touch as comfort regardless of the specific touch pattern, since they assumed the sender was trying to comfort them. "I thought she should know that I was sad and she would try to comfort me. I could feel the warm temperature, and I interpreted it as a comfort. I thought she might want to tell me 'cheer up"' (W16-receiver); "sometimes I don't need to speak, and he'll know what I'm thinking. So, I guess sending a message would not be very hard." (R17-sender). When the context was vague or ambiguous, participants showed adaptability in their interpretation: "I was like, imagining it as if I'm not in the house ... then pressure made sense because she will sometimes hug a pillow or something ... but if I'm there then pressure also makes sense because yeah, she would grab me" (R1-receiver). Context also helped participants adapt interpretation in response to receiving sensations that were different from what they expected. For example, R7 received a cold sensation when her partner had been meaning to send a message of warmth: "with the cold [TE sensation], I thought because it was like a sunny morning, I would be kind of cooled down by that ... but now that [the TE sensation] was warm ... it could be the other way and it'd just feel like heat from the sun. R7-receiver)".

Relationship context was critical to generating and interpreting touch messages, as their design was shaped by the norms of contexts of friendship, partnerships, and work colleagues and the extent to which touching the hand was considered appropriate. Sending pleasant sensations was considered acceptable in most contexts. "(I sent) cold temperature...I want to comfort her, and I was thinking that she said she doesn't like warmth, so I combined this information to make her feel better..." (W1-sender). However, participants in close relationships suggested a partner's touch sensation preferences could be reversed to make meaningful unpleasant touch messages by sending pressure and heat during an argument "because she doesn't like that" (R13-sender). In the context of a romantic-partnership participants wanted to enhance their own physicality, for example, suggesting they send their hand's exact temperature, which would feel natural if they could "put my hand here and it can transfer my temperature to him" (R17-sender).

Some participants also drew on the social norms of touch, commenting that people may not want parts of their hand to be touched in some situations, e.g. comforting a person feeling sad: "I want to comfort her, but I'm also afraid to bother her. I think she may not wish to be touched, and even want to push me away, so I would hold her fingers gingerly with a bit of strength.” (W7-sender). In the work-communication context participants raised gender as a contextual issue in sending and receiving touch. Touch was only considered appropriate between close female colleagues or peers at the same level. However, the workplace was generally perceived as a space where people in power initiated supportive touch, "The boss, if he wants to encourage the subordinate, he can send something like a pat on the shoulder" (S6-sender) and considered to be potentially acceptable via the TE system, pointing indirectly to different acceptability norms attached to different body parts.

\subsubsection{The use of the hand as a complex 'touch' space}

Findings suggest that senders found the hand a complex space for generating touch sensations.

The hand was perceived as composed of regions defined by varying levels of skin sensitivity and distance from the centre of the hand. Touch was shaped by the perception that different hand regions may be more sensitive to and hence better at conveying certain sensations; the palm being more conducive to sensing temperature and fingers tips to pressure and the back of the hand more sensitive to pressure. For example, F3 observed that "Not sure if it feels like touch to me because it's a very like kind of my whole hand that's being touched at the same time. And normally, human touch [is] much more on one part of your hand and not necessarily your whole hand. (F3-receiver)" F1 also pointed that "[with the TE], it was a constant pressure, whereas in reality touch is very specific to many points and varies over time in different degrees (F1receiver)."

Participants highlighted the importance of dynamic touch moving across the different regions of the hand when expressing emotions: "I want to move my hand gently over her hand to comfort her, rather than put it poised over her hand." (W12-sender). Here touch was understood as a flowing process: "you send continuous 
information to the specific parts of the hand through a dynamic touch, ... you control its starting point and the direction of the information flow, and at the same time you modulate the intensity of the pressure and temperature." (W6-sender).

The skin and reactivity of the hand were also important elements. Participants noted the ability to sense who is touching you by the feel of their skin texture and temperature. Some participants equated the lack of skinto-skin contact afforded by the TE with the sense of a distant hand. This sense of distance was also enhanced by the lack of immediate perception of the other's response, as when we touch someone.

\subsubsection{The physicality and agency of touch and its sense of connectedness}

Despite the limitations of the TE devices and lack of skin contact, some participants talked about how mediated touch created a stronger sense of connection.

This sense of connection seemed to arise from its physicality and the emotional responses it generated. For example, for romantic partners this sense of connection and sharing arose from the physicality of the modality, their emotive responses. "I haven't touched you physically, I haven't held your hand, but it's kind of nice. I feel like maybe I've held your hand this whole time." (R10). R11 suggested there was a sense of connection because "I felt like we had a shared experience". This sense of connection generated by the tactile sensation emerged with the other pairs: "I tried to keep the hand warm and put moderate pressure because I thought that was still good to feel connected" (F2-sender). Interestingly, there were differences in the extent to which pressure and temperature each contributed to these factors. R9 implied that having a 'sweaty hand' afterwards contributed to feeling like they had held hands. Some went further, specifying that "the pressure is more of a physical thing [than temperature], like feeling close" (R5) and "the temperature felt a bit more independent ... maybe because it was just in the one spot" (R1-receiver). However, temperature changes were perceived as more emotional than other modalities "[with pressure they felt emotional but] maybe a little, but less [than with the temperature]" (R18-receiver). At the same time, the slow speed of the pressure and temperature functions of the TE led participants to discuss the importance of timing in building natural tactile messages. In unmediated-touch, pressure and temperature changes happen quicker than with the prototype system. "What happens in a handshake? There's an initial slide and there's a squeeze and then there's a release. All three of those require an instant change in temperature and pressure." (F1).

Agency of touch was another significant contributing factor to the participants' sense of connectedness and physicality - the knowledge that the other person was in control of the sensations they received because "whatever's happening in here isn't by your own doing unless you press your own switch, so yeah" (F5receiver). While this sense of physical presence may be interpreted as a stronger connection if the touch is welcome, it may lead to negative feelings and a sense of loss of control when the touch is not desired. W14 said, "I wouldn't like that ... I wouldn't wanna be receiving a moisture feeling (W14-receiver)". Indeed, the sense of connection created through the TE system was perceived differently by work-participants who considered same-sex male touching and male-female touch interaction in the workplace mostly inappropriate, "I don't want to be touched by the opposite gender at work as I feel [it is] very unnatural and I think it's offensive to me." (W1-receiver).

\subsubsection{Conveying affect and emotion by touch}

All participants were able to use touch to express a range of emotions through tactile messages, using the set of modalities and adjusting their intensity and duration during the touch interaction afforded with the TE.

Emotional tactile patterns were visible in the interactions between participants. Tables 2, 3 and 4 present some of the gestures that emerged in relation to the emotions explored within the contexts of friendship, partnerships and work. We provide separate tables given the relevance of contexts, scenarios and relationships in producing and interpreting tactile messages, rather than trying to identify patterns across them. The images comprise annotated stills from the videos or sketches reproduced from the videos dependent on participant permissions of using videos and vary according to the sketching skills of the relevant researcher.

Whilst other touch gestures not including the hands (e.g. hugging, shaking) were mentioned, the tables focus mainly on hand-related gestures given the focus of the paper. The analysis highlights how different regions of the hands (and other body parts in conjunction with the hand) are used within the different contexts and 
emotional scenarios explored. It is interesting to note how different areas of both the hand that touches and the hand that is touched are used to express different emotions together with its kinematics and device modalities. For the sake of conciseness, we refer the reader to the three tables for the pattern details.

Table 2: Study 1 Friendship: Hand gestures used to express emotions (dotted border outlines the area where the touch happens, the arrows symbolize the direction of the gesture movement and the dots symbolize the pressure points where the touch is applied)

\begin{tabular}{|c|c|c|c|}
\hline Emotion & Touch gesture & Description & Device modality \\
\hline Joy/Excitement & & $\begin{array}{l}\text { Grabbing and squeezing } \\
\text { with multiple intense } \\
\text { and fast movements } \\
\text { going up and down. }\end{array}$ & $\begin{array}{l}\text { Unclear } \\
\text { temperature pattern } \\
\text { but dynamic } \\
\text { pressure from low } \\
\text { to high }\end{array}$ \\
\hline Loneliness & & $\begin{array}{l}\text { Reaching out, slight and } \\
\text { small touch with a finger } \\
\text { over the top of their } \\
\text { friend's knuckles to } \\
\text { signalize they are in the } \\
\text { need of something. }\end{array}$ & $\begin{array}{l}\text { Medium pressure } \\
\text { and unclear } \\
\text { temperature } \\
\text { pattern }\end{array}$ \\
\hline Distress & & $\begin{array}{l}\text { Grabbing by the fingers } \\
\text { with a firm grip on the } \\
\text { sides of the hand rather } \\
\text { than from the top of the } \\
\text { hand. }\end{array}$ & $\begin{array}{l}\text { High pressure, } \\
\text { unclear } \\
\text { temperature } \\
\text { pattern. "I felt she } \\
\text { was angry at me or } \\
\text { at a situation } \\
\text { There was much } \\
\text { more pressure and } \\
\text { she used heat as } \\
\text { well which would } \\
\text { mean tha } \\
\text { something's wrong } \\
\text { or that person is } \\
\text { angry." (F3 } \\
\text { receiver) }\end{array}$ \\
\hline
\end{tabular}




\begin{tabular}{|c|c|c|c|}
\hline Relaxed & 7 & $\begin{array}{l}\text { Slight strokes with } \\
\text { fingers over the top of } \\
\text { the friend's hand. Male } \\
\text { participants preferred } \\
\text { grabbing and squeezing } \\
\text { their friends' shoulder to } \\
\text { say, “Isn't it nice here." } \\
\text { (F4-sender) }\end{array}$ & $\begin{array}{l}\text { Medium } \\
\text { temperature and } \\
\text { low pressure } \\
\text { Unless: } \\
\text { associate } \\
\text { relaxation [with the } \\
\text { situation]. It's a hot } \\
\text { day. So, I wanted it } \\
\text { to be cold. (F6- } \\
\text { receiver) }\end{array}$ \\
\hline Comfort & is & $\begin{array}{l}\text { Holding, stroking with } \\
\text { the back of the hand with } \\
\text { their thumb. Others } \\
\text { would use the palm of } \\
\text { their hand to stroke the } \\
\text { shoulder. To reassure, } \\
\text { they would add a } \\
\text { squeeze on the hand or a } \\
\text { shoulder. "Reassurance } \\
\text { is a lot easier to express } \\
\text { by touching someone } \\
\text { rather than worry. } \\
\text { Cause people can tell if } \\
\text { you are worried and } \\
\text { they'll ask you "Are you } \\
\text { okay"? [but what can } \\
\text { you say to reassure](F7- } \\
\text { sender) }\end{array}$ & $\begin{array}{l}\text { Medium pressure } \\
\text { and high } \\
\text { temperature. Slow } \\
\text { stroking. }\end{array}$ \\
\hline
\end{tabular}

Table 3: Study 1 Romantic partners: Frequent gestures of the sender and use of modalities while describing touching their partner in real life. (Arrows symbolize the direction of the movement)

\begin{tabular}{|c|c|c|c|}
\hline Emotion & Touch gesture & Description & Device modality \\
\hline Ecstatic & & $\begin{array}{l}\text { Grabbing and } \\
\text { squeezing: "it'd } \\
\text { probably be quite a } \\
\text { strong grip" (R6), "I } \\
\text { would hold his hand very } \\
\text { tight" (R17-sender) and } \\
\text { "quick squeeze"_(R11- } \\
\text { sender) and demonstrated } \\
\text { by others. } \\
\text { Quick tapping was } \\
\text { demonstrated in line with } \\
\text { the frequently mentioned } \\
\text { desire for a quicker } \\
\text { response from the device } \\
\text { for expressing the high } \\
\text { arousal of this emotion. }\end{array}$ & $\begin{array}{l}\text { Pressure and warm temperature with } \\
\text { either high intensity or high speed of } \\
\text { change }\end{array}$ \\
\hline
\end{tabular}




\begin{tabular}{|c|c|c|c|}
\hline Fear & & $\begin{array}{l}\text { Holding, grabbing and } \\
\text { gripping with strong } \\
\text { grips with little } \\
\text { movement. Grips using } \\
\text { separated fingers, using } \\
\text { fist, using extended } \\
\text { muscles. "I'd be clinging } \\
\text { to him for dear life...it's } \\
\text { a moment of suspense so } \\
\text { I kind of wanted to go } \\
\text { slowly with it so I'm just } \\
\text { gradually grabbing him" } \\
\text { (R15-sender). }\end{array}$ & $\begin{array}{l}\text { High pressure: "definitely felt like the } \\
\text { suspenseful moment when you clench } \\
\text { the muscle tightly" (R10-sender); "it } \\
\text { kind of felt like you know when you're } \\
\text { watching a movie and you're holding } \\
\text { onto someone and you're getting } \\
\text { tighter and tighter and then the scary } \\
\text { part comes" (R14-sender). } \\
\text { Hot temperature (but not warm): "I } \\
\text { feel like I'd be hot in a scary scenario" } \\
\text { (R4); "my heart was racing” (R6). } \\
\text { Cold temperature: "you get cold - } \\
\text { cold, clammy hands" (R3), "I would've } \\
\text { gone for a colder temperature ... chill } \\
\text { down the spine is more like suspense" } \\
\text { (R5). }\end{array}$ \\
\hline Longing & & $\begin{array}{l}\text { Light and soft stroking } \\
\text { using back of hand or } \\
\text { just the thumb: } \\
\text { "holding someone's hand } \\
\text { quite gentle the whole } \\
\text { time" (R12-sender) and } \\
\text { "a cold light touch ... } \\
\text { probably just the back of } \\
\text { my hand" (R10-sender). } \\
\text { Other massage-like } \\
\text { movement was } \\
\text { commonly brought up or } \\
\text { demonstrated "a lot of } \\
\text { like rubbing," (P16) or } \\
\text { "a massage maybe" } \\
\text { (P18). }\end{array}$ & $\begin{array}{l}\text { Steady limited amount of pressure: "I } \\
\text { wouldn't want bare pressure, I'd just } \\
\text { want it to be like relaxed” (R15); “if } \\
\text { there was too much pressure, I'd feel a } \\
\text { bit overwhelmed”_(R16-receiver);_ “it } \\
\text { felt very sexual” (R6receiver). } \\
\text { Gentle warm temperature to simulate } \\
\text { the warmness from the contact of the } \\
\text { skin. Cold temperature was used to } \\
\text { suggest the need to be touched and } \\
\text { warmed. }\end{array}$ \\
\hline Relaxed & & $\begin{array}{l}\text { Hand on top, flat or } \\
\text { cupping: "not like a hold } \\
\text { but just like you know, a } \\
\text { hand on top" (R6); "my } \\
\text { hand on top of yours } \\
\text { rather than holding } \\
\text { hands... laying my hand } \\
\text { on top or cupping my } \\
\text { hand on top to fit yours } \\
\text { better" (R10). }\end{array}$ & $\begin{array}{l}\text { None, or very light pressure (and no } \\
\text { noise): "if it was more controllable and } \\
\text { you could choose just a tiny amount } \\
\text { pressure ... sort of slightly touching } \\
\text { each other ... then I would choose that" } \\
\text { (R1-sender). "it's just about quietness, } \\
\ldots \text { if the [pressure] noise was } \\
\text { completely quiet, then maybe like a } \\
\text { little bit of pressure, if it maintained } \\
\text { that level, would be nice”. } \\
\text { Warm temperature (but not hot): } \\
\text { "when you're feeling peaceful, you're } \\
\text { probably happy, and you're feeling } \\
\text { warm" (R4); "somewhere between hot } \\
\text { and cold - that's what you feel when } \\
\text { you're at peace" (R11). }\end{array}$ \\
\hline
\end{tabular}


Table 4: Study 1 Work context: Some gestures that emerged from workers' reports. Such gestures emerged from considering known co-workers in daily practices, as reported in the post study phase.

\begin{tabular}{|c|c|c|c|}
\hline Emotion & Touch gesture & Description & Device modality \\
\hline Anger & & $\begin{array}{l}\text { Strong grasping } \\
\text { and slapping. }\end{array}$ & $\begin{array}{l}\text { High or cold temperature } \\
\text { From warning to anger, modulated } \\
\text { by amount of pressure: "I would feel } \\
\text { a relatively high pressure as the } \\
\text { supervisor is very angry, and I feel a } \\
\text { bit pain when I imagining this action,, } \\
\text { and it brings me some hot feelings." } \\
\text { (W16-receiver). But for warning "I } \\
\text { didn't want to use pressure to make } \\
\text { him uncomfortable. I just wanted to } \\
\text { warn him, and the [medium] pressure } \\
\text { was a deterrent." (W13-receiver) }\end{array}$ \\
\hline Comfort & & $\begin{array}{l}\text { Fingers or hand } \\
\text { holding and gentle } \\
\text { stroke or patting. } \\
\text { The hand is touched } \\
\text { only in a specific } \\
\text { part: fingertips or } \\
\text { centre of the back of } \\
\text { the hand with only } \\
\text { partial hand. } \\
\text { Patting } \\
\text { shoulder/head: "I } \\
\text { gave him a little } \\
\text { pressure to comfort } \\
\text { him, like a simple pat } \\
\text { on his head, or } \\
\text { shoulder, and saying } \\
\text { 'Listen to me', 'don't } \\
\text { feel so badly'." } \\
\text { (W13-sender) }\end{array}$ & $\begin{array}{l}\text { Gentle pressure. During grabbing the } \\
\text { pressure is felt the side of the hand } \\
\text { rather than on the top of the hand } \\
\text { Medium temperature. "I sent } \\
\text { warm...I thought she might need some } \\
\text { warmth...I just wanted to let her know } \\
\text { I would be with her, and she was not } \\
\text { alone. But I didn't turn the } \\
\text { temperature too hot for fear she would } \\
\text { be uncomfortable." (W15-sender) } \\
\text { Responses: heat to express their } \\
\text { gratitude; cold to express lack of relief } \\
\text { by the support or to be left alone }\end{array}$ \\
\hline
\end{tabular}




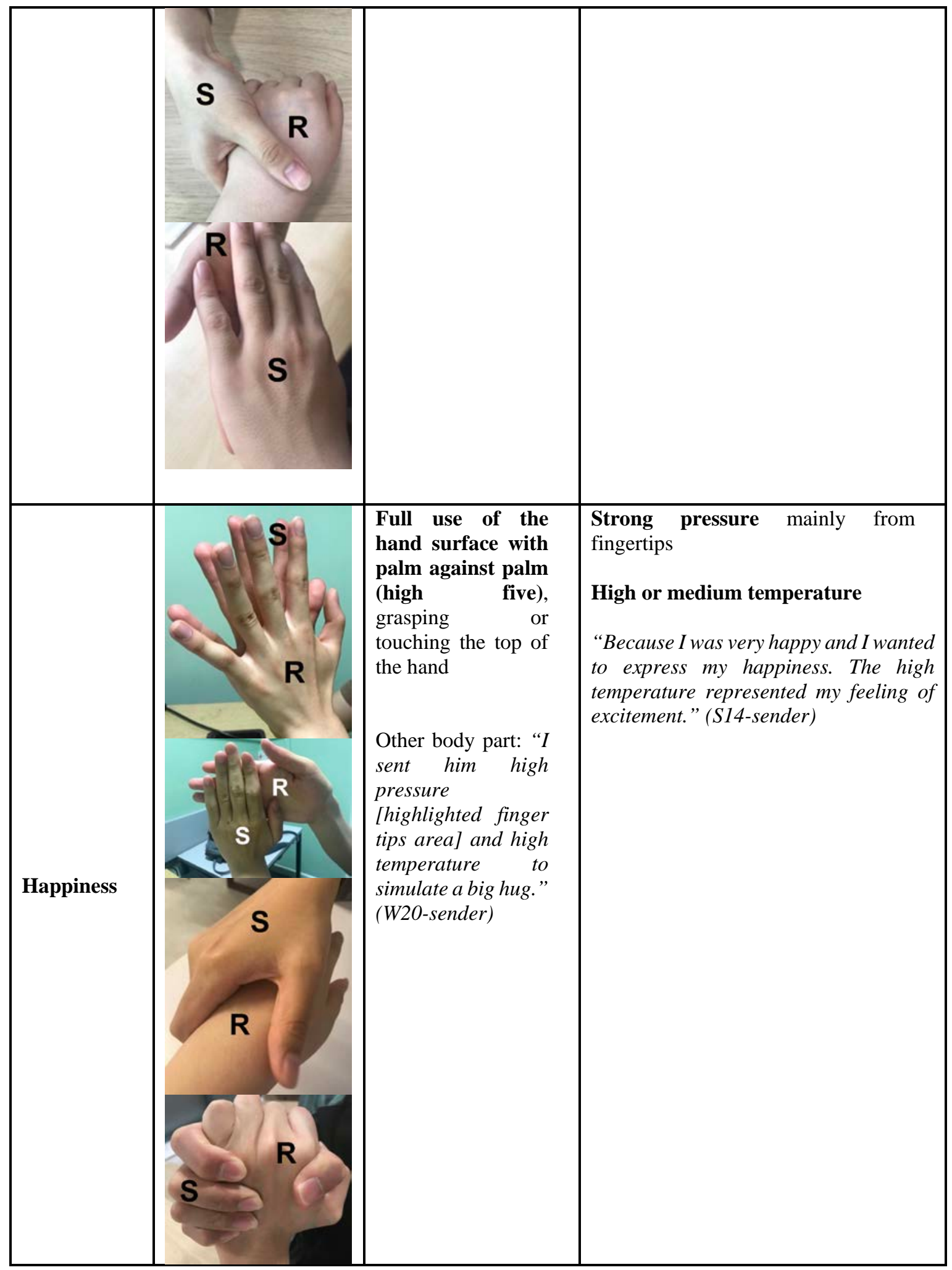

How emotion shaped the directionality of or the desire for tactile interactions emerged as an interesting element of conveying affect and emotion by touch including: i) a bidirectional need/openness to send, receive 
and respond to touch; ii) being open to receive touch but not to touch; and iii) a need to touch but not to be touched. Below we provide some illustrative examples of this.

Participants commented on the significance of the need to touch to reassure and its possible reciprocity. Touch when offering comfort and support (e.g., in response to a person being lonely, sad, distressed, and as a way of providing a sense of security), a participant commented: "I want to hand in hand, and tell her 'I'm here'. I think it can bring her sense of security and dependency" (W8-sender). Several participants commented that when they felt lonely or distressed, they would expect to receive reassuring or comforting touch. "... reassurance is a lot easier to express by touching someone" (F7-receiver), "If we would both know that I am worried I would be expecting the other party to show support" (F9-receiver). In the sadness scenario, senders sent warm touch in an attempt to show they care and create a sense of security: "I sent warm...I thought she might need some warmth...I just wanted to let her know I would be with her, and she was not alone. But I didn't turn the temperature too hot for fear she would be uncomfortable" (W15-sender). Other senders used heat to convey intense positive emotions, such as encouragement and cheering up. Many participants used low pressure to simulate some comforting actions commonly used in life such as a hug or a back pat. "I gave him a little pressure to comfort him, like a simple pat on his head, or shoulder, and saying 'Listen to me', 'don't feel so badly'” (W13-sender). To respond to the comforting touch, some receivers sent heat back to express their gratitude, although one receiver sent cold to express sadness that they did not get relief or that they did not want to be touched.

In contexts of joy and excitement, participants expected an openness to being touched, and for others to initiate touch “... if it's my accomplishment, I don't want to tell someone. I would want to be hugged. I'd be proud of myself. I don't want to reach out.” (F5-sender that thinks she should be a receiver). Touch messages to share excitement also depended on who was experiencing the main cause of such an excitement. "If it's like you got into the university, then I would also give a hug. But if she comes to me and says my family member is having a child, I wouldn't necessarily touch my friend and say, "That's great." (F3-sender). Senders across the different scenarios employed heat and high pressure to express intense excitement and happiness, with some associating high pressure with a big hug: "I sent him high pressure and high temperature to simulate a big hug." (W20-sender). Intensity of touching and the associated use of high pressure emerged in the Romantic partner study, to provide "a strong grip” (R16) or holding hands "very tight” (R17). Generally, they wanted a stronger sensation for all the different tactile modalities: "I'd just want solid pressure, it's more like intense than loads of little ones because this is a big deal, my promotion" (R5-sender); or "I would do the pressure to the max" (R15-sender). R3 also linked temperature changes to speed, expressing that "it doesn't go hot or cold fast enough".

Differently from positive or low arousal emotion, touch can be perceived as a means for demonstrating anger and rejection. Participants chose extreme temperatures to express anger and sent cold sensations to express a sense of distance. Some used patterns of alternating cold and heat to convey anger: "At first I sent cold and then I turned temperature up... alternating cold and hot feelings would make her painful" (W11-sender). They also conveyed anger via high pressure, e.g., to emphasize the seriousness of a situation, "High pressure reflects the angry emotion. It's like a hard slap on the hand" (W16-sender). "I didn't want to use pressure to make him uncomfortable. I just wanted to warn him, and the pressure was a deterrent” (W13-sender).

\subsection{Study 1: Summary}

The above findings illustrate the myriad of emotions and affect conveyed through remote touch, and the subsequent complexity toward developing meaningful digital touch messages using pressure and temperature. They also highlight the important role of context, both situation and relationship in generating physical sensations and the meaning of touch. Tactile messages emerged as dynamic patterns rather than static implementation. Areas of the hands and modulation of haptic sensations contribute to create complex dynamic exchanges. Yet, overall participants were positive that a 'non-verbal language' through tactile 'codes' would develop over time, suggesting that "eventually we'd just get used to certain signals that are being sent” (R14). 


\section{Study 2: Creation and interpretation of touch messages}

Study 2 was designed to 'unpack' and investigate the detailed process of creation and interpretation of touch messages. It focused on understanding the underlying decisions in the process of designing and creating touch messages, examining participant practices and patterns of composing and interpreting tactile messages, and how the addition of vibration as a resource for tactile communication influenced these. In response to Study 1 findings that the use of touch was particularly sought in negative emotional scenarios and that negative emotional states triggered touches to generate positive emotions, Study 2 used scenarios focused on three 'negative' emotions closely connected in terms of valence-arousal space.

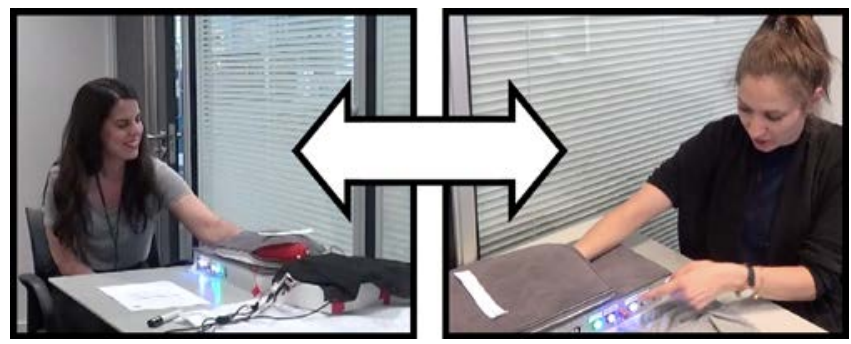

Figure 2: Study 2, Use of Tactile Emoticon devices situated in separate rooms

\subsection{Participants}

Six participant pairs were recruited: 3 friendship pairs (of $1-12$ years duration) and 3 family member pairs (two sets of partners and one mother and child). Five participants were male and 7 were female, ranging from 12 to 55 years of age. F refers to friendship participants; and M refers to family member participants.

\subsection{Procedure}

Study 2 followed a similar procedure to Study 1, with the following significant adaptations:

- $\quad$ The TE devices both included vibration, as well as temperature and pressure.

- Recruitment from researcher networks focused on length or depth of participant relationships.

- $\quad$ TE set up enabled participants to be located in separate rooms to exchange messages (Figure 2, with written consent to publish photos), better simulating remote communication and ensuring no spoken or non-verbal communication, beyond the experience via the TE system.

- A focus on message creation and interpretation in which each scenario consisted of two parts, where each participant was the sender in one scenario and receiver in the next. A written description of each scenario was given to the respective sender or receiver, and verbally conveyed to them by the accompanying researcher. For each scenario, the sender was asked 'What message would you like to convey and how would you do this with the touch device?'. The receiver was asked 'What tactile experience are you getting? What message do you think your partner is trying to convey? How does this make you feel?' (Table 5).

- During interaction with each device participants were asked to verbally describe their interpretation of the messages they received, as well as their physical sensations (this was inaudible to their partner participant).

- All sessions were video-recorded: two cameras were used, one camera was set up to capture each participant's interaction with the device; how they used the device, their gestures and facial expressions. One camera recorded the pre and post interaction discussion with both participants together.

\section{Table 5: Study 2 scenarios}

\begin{tabular}{|l|l|l|}
\hline Scenario & $\begin{array}{l}\text { Sender } \\
\text { For each scenario: What message } \\
\text { would you like to convey and how }\end{array}$ & $\begin{array}{l}\text { Receiver } \\
\text { For each scenario: What tactile experience } \\
\text { are you getting? How does this make you } \\
\text { feel? What message do you think your friend }\end{array}$ \\
\hline
\end{tabular}




\begin{tabular}{|c|c|c|}
\hline & $\begin{array}{l}\text { would you do this with the touch } \\
\text { device? }\end{array}$ & $\begin{array}{l}\text { is trying to convey? What could the sender do } \\
\text { differently to make you feel better? }\end{array}$ \\
\hline $\begin{array}{l}1 \\
\text { Communicating } \\
\text { love (sad/lonely) }\end{array}$ & $\begin{array}{l}\text { Imagine your friend/partner is } \\
\text { working away from home, in a } \\
\text { different time zone, with little } \\
\text { opportunity to talk to you. He/she is } \\
\text { feeling lonely/sad. }\end{array}$ & $\begin{array}{l}\text { You are working away from home in a } \\
\text { different time zone, it is difficult for you to } \\
\text { talk to your friend, and you are feeing sad and } \\
\text { lonely. }\end{array}$ \\
\hline $\begin{array}{l}2 \\
\text { Communicating } \\
\text { love (fun and } \\
\text { excitement) }\end{array}$ & $\begin{array}{l}\text { Imagine your friend/partner is } \\
\text { working away from home, in a } \\
\text { different time zone, with little } \\
\text { opportunity to talk to you. You are } \\
\text { experiencing something exciting and } \\
\text { fun. }\end{array}$ & $\begin{array}{l}\text { Your friend/partner is working away from } \\
\text { home, in a different time zone, with little } \\
\text { opportunity to talk to you. They are } \\
\text { experiencing something exciting and fun. }\end{array}$ \\
\hline $\begin{array}{l}3 \\
\text { Social rejection } \\
\text { (social exclusion/ } \\
\text { party) }\end{array}$ & $\begin{array}{l}\text { Imagine your friend/partner is at a } \\
\text { social gathering, where nobody talks } \\
\text { to them. He/she is feeling rejected, } \\
\text { excluded. }\end{array}$ & $\begin{array}{l}\text { You are at a social gathering, where nobody } \\
\text { talks to you. You are feeling rejected and } \\
\text { excluded. Your partner/friend send you a } \\
\text { tactile message }\end{array}$ \\
\hline $\begin{array}{l}4 \\
\text { Social rejection } \\
\text { (interview) }\end{array}$ & $\begin{array}{l}\text { Imagine your friend/partner's } \\
\text { professional talk/interview went } \\
\text { badly. She/he is experiencing low } \\
\text { esteem, low confidence, and } \\
\text { embarrassment. }\end{array}$ & $\begin{array}{l}\text { Your professional talk/ interview went badly, } \\
\text { and you are experiencing low esteem, low } \\
\text { confidence, and embarrassment. }\end{array}$ \\
\hline $\begin{array}{l}5 \\
\text { Comfort in pain/ } \\
\text { illness (chronic } \\
\text { pain) }\end{array}$ & $\begin{array}{l}\text { Imagine your friend/partner has } \\
\text { chronic back pain that has strongly } \\
\text { affected their life. They are at work, } \\
\text { feeling in pain and misunderstood by } \\
\text { colleagues. }\end{array}$ & $\begin{array}{l}\text { You are suffering from chronic back pain that } \\
\text { has strongly affected your life. You are at } \\
\text { work, feeling in pain and feeling } \\
\text { misunderstood by colleagues. Your } \\
\text { friend/partner sends you a tactile message. }\end{array}$ \\
\hline $\begin{array}{l}6 \\
\text { Comfort in pain/ } \\
\text { illness (acute } \\
\text { pain) }\end{array}$ & $\begin{array}{l}\text { Imagine you are away, and your } \\
\text { friend/partner is experiencing acute } \\
\text { pain and he/she is worried about it. }\end{array}$ & $\begin{array}{l}\text { You are experiencing acute pain and you are } \\
\text { worried about it. Your partner /friend sends } \\
\text { you a tactile message. }\end{array}$ \\
\hline
\end{tabular}

\subsection{Data analysis}

Qualitative video data from the interaction and semi-structured interviews were analysed. Videos were timemarked and transcribed using ELAN software. Thematic analysis was informed by sensorial and multimodal aspects of communication [41], focusing on meaning-making around touch as a technology mediated process, which involves the sensorial, physical and modal aspects of sending and receiving messages. The first analytic strand focused on how participants used the technology to construct and send digital touch messages in specific contexts using the available tactile actuation methods. The second analytic strand focused on the receiving and interpretation of touch. Both strands drew on video data from the interaction with the TE and from participants' comments in the post interaction discussion.

Three phases of analysis were undertaken. The first focused on descriptions of the sender actions (which buttons were pressed) together with their descriptions of the physical sensations sent, and the receiver description of sensorial and physical sensations experienced. The aim here was to bring to light how the different tactile actuation methods (temperature and pressure, and vibration) were used, and the physical sensations of touch that these conveyed. The second phase looked at the communicative meanings attributed to the different elements of the digital touch communication with TE (i.e., touch properties: vibration, temperature and pressure; regulators: duration, intensity, repetition) i.e., the associations, social norms and communicative resources that participants brought to them. The third phase involved a holistic view of sender and receiver data to explore meaning-making, processes of interpretation, how participants made sense of these messages, as well as breakdowns in communication. 


\subsection{Findings and discussion}

The findings firstly focus on how participants created and generated messages using haptic sensations (pressure, temperature and vibration) at a distance, then on how they interpreted these touch messages.

\subsubsection{Sender generation of touch messages}

Analysis focused on the process of creating and generating touch messages to understand how participants 'designed' tactile sensations by taking specific details of the context into consideration, including tactile identity (whether they like to be touched), and reflecting on their own touch preferences, to enable them to manipulate and combine the haptic sensations (temperature, pressure, vibration) into meaningful sequences. The analysis did not show universal patterns of intended meaning associated with touch properties. However, it did show higher use of pressure and temperature than vibration across the scenarios as a whole (Figure 3) and revealed patterns in how the haptic sensations were used. Pressure was included in nearly all messages to support someone feeling sad and lonely and was associated with various everyday touch practices (stroking, hugging or squeezing the hand), as well as a sense of presence. Temperature was present in the majority of the messages exchanged in the acute pain scenario, indicating a perceived association between the role of temperature (either heat or cold) and pain relief, and comfort. Vibration seemed particularly important, in 'conveying excitement', through rapid repeated use within one message. This suggests a link between excitement and movement (here vibration), perhaps akin to jumping up and down. However, vibration was minimally used across other scenarios, particularly those that involved pain, both emotional and physical. This confirms Study 1 findings that participants identify temperature and pressure as being more useful in 'comforting' contexts through the sense of presence and physicality they convey, or a sense of familiarity of these sensations mapped to physical touch, which does not normally equate to 'vibration'. This is interesting in the current climate of haptic devices which typically use vibration as the tactile element for touch communication.

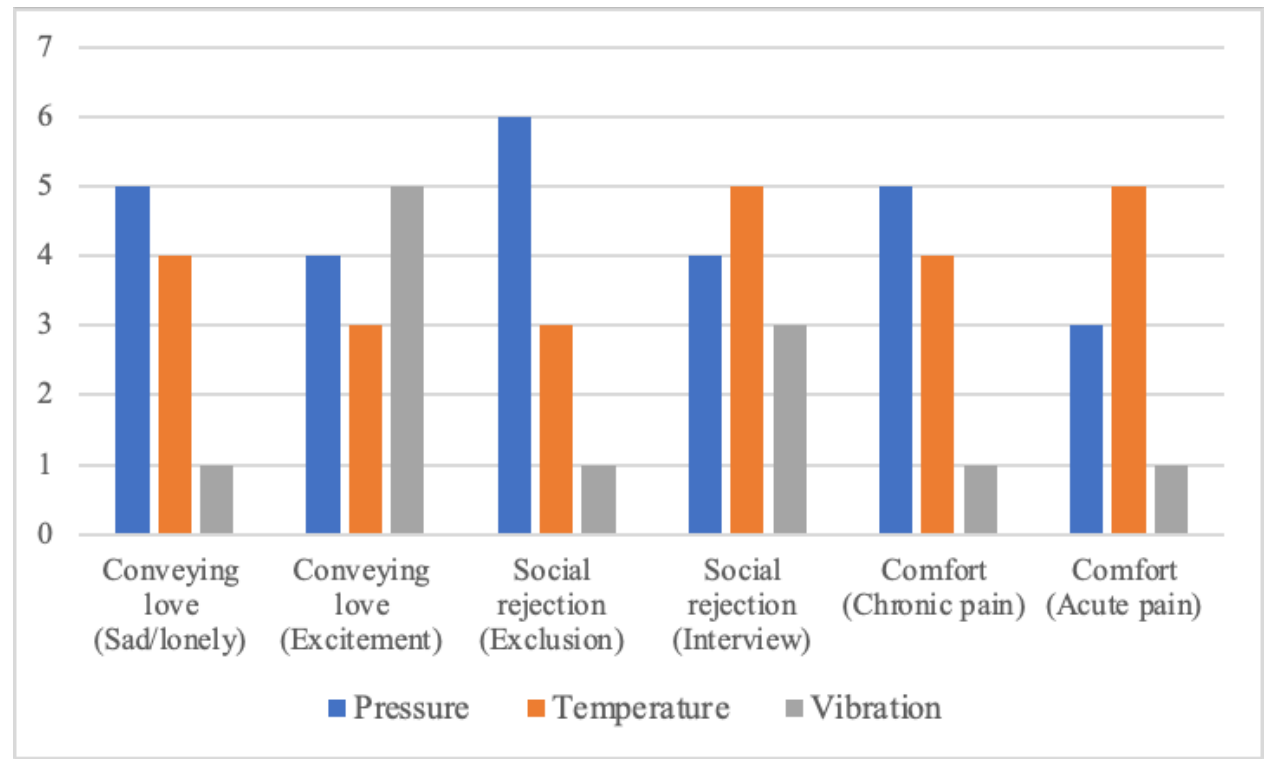

Figure 3: Touch elements used per message sent in each scenario [numbers shown are out of 6 possible uses].

The regulating factors of duration (e.g., switching on and off) and intensity (e.g., amount of pressure or warmth), in touch message design emerged more clearly in Study 2, together with two additional factors: repetition and randomness.

Duration included the duration of the message as whole, and the duration of specific properties of the message. For example, F5 wanted to convey a short (warm) message using vibration because she knew her friend did not like to be touched, especially when upset. Yet, the same participant used a prolonged vibration to convey a message of "cheering up", because change of mood requires time and "does not happen 
instantly". A prolonged vibration was also used to convey continuous support and a feeling of "being there" (M11), while a prolonged squeeze or hug was equated with intimacy and something you would do with your partner (F9).

Intensity was mainly evident with pressure, and temperature, participants differentiating their digital tactile messages by varying the intensity to be felt by the receiver. Higher degrees of pressure were typically related to the desired firmness of the touch, and were associated with a message of support, holding and presence (M11).

Repetition was evident in relation to pressure, often associated with specific physical touches: mimicking a stroke, squeezing the hand. Participants associated pressure repetition with expressing messages of continuous concern and trying to make the other person feel better (M12), through a more prolonged form of touch communication.

Randomness of configuration was evident on two occasions in the 'exciting' scenario, where senders changed actuation methods randomly (M2) and frantically (F10) i.e., each of the three methods started and stopped, without following a specific pattern.

Confirming the importance of context, participants messages relied on some learned associations of touch with a given emotion, and used their own sensation preferences, and/or knowledge of the recipient to design their touch messages. When sending a touch, participants explicitly took the time to consider what touch friends or partners would consider pleasant or unpleasant: "I tried to keep the hand warm and put moderate pressure, because I thought that was still good to feel connected. But she told us that when the pressure got high, she felt like someone was crushing her hand. That's why I tried to be more-gentle and adjust my pressure towards her own perception" (M2). For some, warmth was associated with affection, strong pressure and heat had negative associations, while a cold sensation without pressure associated with a mellow feeling. "I tend to think warm is good, cold is bad, pressure is good, no pressure is nothing" (M1). However, pressure also signified a connection: "Loneliness... I kind of think of cold as feeling sad and lonely and alone and I didn't use pressure because it would mean somebody being there" (M2).

Feedback from the device was considered a critical element in the meaning generation process. Several participants wanted to test the messages they were composing to understand what the message would feel like before sending. However, the post interaction discussions revealed it was not enough to simply know what sensory message you were sending, it was also important to have an idea of the receiver's reaction to it. "I would expect that it would be a modality that would complement, if I do touch on my iPhone and I am sending a touch heart to my partner .. I get his reaction, I sent him a heart the other day and he went "ohhh". So, it is weird that there was no feedback" (F10). Typically, human-human touch not only involves perceiving the reaction of the other to your touch, but also your own emotion or response on touching or being touched by someone else. Furthermore, reaction to touch is not always tactile as shown in the above example and confirmed by other participants who mentioned the value of verbal and facial expression responses as well as tactile (e.g., hugging someone back). Understanding the reaction of the other person was critical for participants to understand if their tactile message fulfilled its purpose and shaped the continuation of the tactile communication. The importance of receiving another's reaction became particularly obvious for the participant with a sensitivity to vibration, who experienced 'vibration' as uncomfortable. Since the sender was unaware of this, they continued to compose messages using vibration.

\subsubsection{Receiver interpretation of touch messages: haptic sensations, intended sentiment}

When participants received touch messages, they first identified the physical and sensorial properties of touch (pressure, touch, vibration), and drew on the context (scenario and relationship) to negotiate the ambiguity of touch as a communicative resource and attribute meanings to the touch message. The construction of meaning comprised three key aspects: the physical touch sensation (e.g., stroking, gentle touch, ticklish); the intended sentiment of the digital touch (e.g., capturing attention, soothing, reassurance); or an emotional state (e.g., excitement).

While in this finding partly echoes those of Study 1 , that is participants were typically able to perceive the different haptic sensations of the messages they received, Study 2 found that some participants occasionally mistook vibration for pressure, and experienced some ambiguity in discerning subtler nuances of temperature, 
due to the warmth of the TE material or their own hands. A hand situated in the TE is already being touched by the material, providing sensations of warmth and softness without any tactile message. In addition, it was difficult for the sender to assess the level of pressure being sent making subtle nuances of communicated pressure challenging.

In terms of communicative intent, the analysis shows several instances where sender intention and receiver interpretation were similar, with a few that were less successful. Table 6 shows examples from each scenario of the tactile message inputted into the device, the sender's intended touch message and the receiver's sensory interpretation.

\section{Table 6: Examples of sender input, sender intended messages and receiver interpretations}

\begin{tabular}{|c|c|c|c|}
\hline Scenario & Device input & Sender Touch Intention & Receiver Interpretation \\
\hline $\begin{array}{l}\text { Scenario } \\
\text { (love) } \\
\text { M11-M12 }\end{array}$ & $\begin{array}{l}\text { Repeated pressure } \\
\text { and heat }\end{array}$ & $\begin{array}{l}\text { Hug and/or squeezing hand for } \\
\text { conveying affection }\end{array}$ & $\begin{array}{l}\text { Pressure and heat is a hug } \\
\text { (Hug feels warm) } \\
\text { Repetition means continued } \\
\text { concern }\end{array}$ \\
\hline $\begin{array}{l}\text { Scenario 2: } \\
\text { (Fun and } \\
\text { excitement) } \\
\text { M11-M12 }\end{array}$ & $\begin{array}{l}\text { Vibration pressure } \\
\text { and heat }\end{array}$ & $\begin{array}{l}\text { Vibration to capture the } \\
\text { attention, pressure and warmth } \\
\text { to convey a hug (whole body) }\end{array}$ & $\begin{array}{l}\text { Pressure is closeness, } \\
\text { vibration excitement and } \\
\text { ongoing process. Feels } \\
\text { tickling around the hand }\end{array}$ \\
\hline $\begin{array}{l}\text { Scenario } 3 \text { : } \\
\text { (social } \\
\text { exclusion/ } \\
\text { party) } \\
\text { F5-F6 }\end{array}$ & $\begin{array}{l}\text { Warmth and } \\
\text { Vibration }\end{array}$ & $\begin{array}{l}\text { Warmth to convey comfort } \\
\text { Vibration was conveying 'fun' } \\
\text { to improve the mood }\end{array}$ & $\begin{array}{l}\text { Vibration interpreted as a } \\
\text { stroke on the arm } \\
\text { Temporal issue raised: you } \\
\text { can't cheer up instantly }\end{array}$ \\
\hline $\begin{array}{l}\text { Scenario } \\
\text { (social } \\
\text { rejection/ } \\
\text { interview) } \\
\text { F5-F6 } \\
\end{array}$ & $\begin{array}{lr}\text { Vibration. } & \text { Not } \\
\text { sure } & \text { about } \\
\text { temperature level } \\
\text { (hands too warm) }\end{array}$ & $\begin{array}{l}\text { Stroke on the arm } \\
\text { Short because F6 doesn't like to } \\
\text { be touched very much } \\
\text { No hug (in a physical space like } \\
\text { a party you need to be implicit) }\end{array}$ & $\begin{array}{l}\text { Short duration led to } \\
\text { ambiguity in interpretation } \\
\text { Would like: vibration to } \\
\text { convey cheering up, pressure } \\
\text { for comfort }\end{array}$ \\
\hline $\begin{array}{l}\text { Scenario 5: } \\
\text { (chronic pain) } \\
\text { M11-M12 }\end{array}$ & $\begin{array}{l}\text { Pressure (midway) } \\
\text { and heat. }\end{array}$ & $\begin{array}{l}\text { Emotional support } \\
\text { Holding, trying to help feel } \\
\text { better }\end{array}$ & $\begin{array}{l}\text { Intimate pressure, heat linked } \\
\text { to healing. More intimate } \\
\text { rather than a strong hug. } \\
\text { Reassuring and supportive }\end{array}$ \\
\hline $\begin{array}{l}\text { Scenario 6: } \\
\text { (acute pain) } \\
\text { M11-M12 }\end{array}$ & $\begin{array}{l}\text { Pressure (repeated } \\
\text { twice) and cold. }\end{array}$ & $\begin{array}{l}\text { Supportive hug and pressure } \\
\text { sensation. More like a pressure. } \\
\text { Vibration not appropriate in this } \\
\text { case because it is shaky and } \\
\text { increases anxiety }\end{array}$ & $\begin{array}{l}\text { Cold is puzzling } \\
\text { Warm is support. } \\
\text { Pressure interpreted as: "I } \\
\text { know you want a hug, so I am } \\
\text { sending you one”. }\end{array}$ \\
\hline
\end{tabular}

As Study 1 participants imagined (but did not experience or evidence), idiosyncratic personal meanings were developed between close friends, family and partners, who successfully designed their touch communication drawing on associations with certain properties of touch that built on their shared touch histories or accounting for the known 'touch profile' of the other. For example, for M7-M8 the property of heat was strongly associated with M8 (his body was perceived by his partner as very warm). This resulted in using heat as a means of introducing identity in the touch messages ("Warmth - we have a thing, especially in the summer M7 thinks I am too warm, so she would know that that's me"). M8 used temperature in two out of the three messages they sent and M7 immediately identified that temperature was an identity of their partner's touch. Shared history with the other plays an important role in successful message communication [13]. These idiosyncratic messages also demonstrate the flexibility and power of touch communication to evolve as well as adapt and become personalized, rather than have fixed meanings. For example, this same pair suggested 
developing a 'dinner' touch - a specific tactile message that means 'dinner is ready' - when discussing possible uses of the system.

Some messages were found to be more ambiguous (Table 7). In example A (social rejection), manipulating the duration of the message (short) to take into account the 'touch profile' of the other person, resulted in some ambiguity about the intended meaning for the receiver, and their expressed preference for a longer message, which would have been perceived as more comforting.

\section{Table 7: Ambiguity of meaning}

\begin{tabular}{|c|c|c|}
\hline Scenario & Sender & Receiver \\
\hline $\begin{array}{l}\text { Example A } \\
\text { Scenario: } \\
\text { rejection }\end{array}$ & $\begin{array}{l}\text { F5: I would do something like that (strokes } \\
\text { her arm light touch) - a bit, but not too much]. } \\
\text { I want it short I also want it warm. } \\
\text { R: Why do you want it to be short? } \\
\text { F5: Because like, I think about F6, I am } \\
\text { different and I like touch. F6 is not ... } \\
\text { especially if she was upset I am not sure if she } \\
\text { would like that, so you take into } \\
\text { consideration the person. } \\
\text { R: Can you show me how this message how it } \\
\text { feels } \\
\text { F5 taps her fingers softly on top of the device }\end{array}$ & $\begin{array}{l}\text { F6: I guess if it lasted longer it } \\
\text { might be more comforting - than } \\
\text { a short one -it made me unsure } \\
\text { of what was the message }\end{array}$ \\
\hline $\begin{array}{l}\text { Example B } \\
\text { Scenario: Conveying } \\
\text { Love/ Excitement }\end{array}$ & $\begin{array}{l}\text { R: What message are you sending? } \\
\text { M2: I am just pressing the buttons, randomly }\end{array}$ & $\begin{array}{l}\text { M1: I think he is heating me up - } \\
\text { very hot in there. It is vibrating. } \\
\text { He is sending pressure } \\
\text { M1:I think he is trying a lot of } \\
\text { things I am not sure. I would } \\
\text { think of it as, as exciting because } \\
\text { he is showing off all the things } \\
\text { that he can do. He is trying all } \\
\text { the features. So, I guess that is } \\
\text { excitement. Sort of showing what } \\
\text { he is engaged with }\end{array}$ \\
\hline
\end{tabular}

In example B (conveying excitement), the randomness of the tactile inputs sufficiently communicated the intended emotion to M1. Here there is a level of unpredictability in the design of the tactile experience, which cannot be mapped to an experienced physical tactile sensation, suggesting the potential of a new type of touch experience shaped by the functionalities of the technology provided.

Situations where a receiver was typically unable to interpret the intended meaning included: a) a specific kind of touch that was not pleasurable (e.g. sensitivity to vibration); b) a touch message directly contrasting with an individual's meaning associated with a particular physical sensation within the scenario (e.g. cold means anger); c) participants who needed time to familiarize with mediated touch communication (M2 demonstrated difficulty in interpreting messages received at the beginning, although this changed as communication progressed) and d) very short messages, resulting in confusion between accidental and intended touch.

Although the devices focus touch sensations on the hand, several participants mentioned that their messages were intended for other parts of the body or were interpreted as such. This suggests that the devices at times might have functioned as referential objects in the sense that they were used as instruments to trigger a touch sense that drew on a participants' everyday tactile practices, shared meaning and experiences. 


\section{General Findings and Discussion}

In this section, we first discuss four key social dimensions that emerged as critical for the design of touch technology: presence, identity, control and privacy (summarised in Table 8). A sense of presence and identity emerged as a precursor to the interpretation of exchanged tactile messages and led to two levels of communication taking place (presence/identity vs emotional/content of the message). Notably, we discuss how people's concerns and preferences regarding identity and privacy contributed to the context of the interpretation of tactile exchanges. Second, we discuss how the study results provide further insights into the physical dimensions of tactile interaction (modalities) linked to affective remote touch and could contribute toward richer and more 'natural' remote tactile experiences (summarised in Table 9) and the dynamics of tactile interaction and affective meanings (Table 10).

\subsection{Tactile presence, identity, control and privacy}

Physical presence, identity and privacy emerged as critical social dimensions of participants' tactile interaction with the system. While previous studies (e.g. [19]) focused on the use of modalities in building emotional meanings, our work highlights how touch modalities contribute to building such social context. Table 8 summarises how these are realized and the key related design requirements that emerged, each discussed below.

\subsubsection{Tactile Presence}

Touch is a significant non-verbal channel that allows us to sense the physical presence of others. When touch is not possible, other channels, either verbal or non-verbal, are not able to fully compensate for the vacuum that is left by this lack of physical connection. For the majority, this lack is felt as significant given the effect that touch has on our physiology, wellbeing and even development [20]. As such, the sense of physical presence is considered a critical dimension that technology-mediated touch needs to deliver. In all of the study scenarios, the requirement of a sense of presence was a constant theme of participants' responses. The sense of presence that touch offers was the first message that they took from the tactile exchange supported by the TE system, "knowing that the other was there for/with them". As discussed in section 2, various studies have shown that delivering a haptic touch concurrently with other visual representations of a person or social agent enhances the sense of presence provided by those representations $[12,81]$. Our results extend this work by demonstrating how the sense of presence provided by physical synthetic touch e.g., through pressure and temperature, can be used to enhance the sense of presence through digital touch, including mimicking the natural sensations evoked by physical social touch (e.g., skin temperature) as detailed in the next section. Participants also felt that the sense of presence was reinforced by knowing that the tactile gestures were created rather than predefined (as in many digital touch devices, e.g. $[66,80]$ ) and even re-experienced by the sender as a form of sharing.

Another interesting finding in relation to presence was sweat sensation. Whilst our devices were not purposely designed to create sweat, the glove material as well as the pressure and heat actuators contributed to generating sweat on the hand of the receiver and to a certain extent on the sender. People talked about heat and sweat as important to the sense of presence. This is in line with VR [58] and neuroscience studies [61] showing that all feedback we receive that are concurrent with the action made or received contribute to form a specific illusion. The sweat sensation prolonged the feeling of having been together. Nonetheless sweat, as expected, was not always a positive sensation. Its acceptability is affected by many factors, such as the relationship with the other person or the environmental temperature. As such, it needs to be carefully considered in the design; in particular, environmental temperature may differ between two remote sites. This suggests that the system may have to provide a feeling of each other's environmental temperature, raising the opportunity to design for the creation of shared touch space. While the shared space has been mentioned in other studies (e.g., perceived distance from each other through visualization [65]), the effect of environment on sensations has not been considered. In the case of our 'mitt', we could imagine that the mitt becomes the shared environment and baseline temperature for such a shared environment could be set by the two people. 


\subsubsection{Tactile identity}

Whilst most studies have focused on the effect of relationship on remote touch (e.g. [56,66]), our findings highlight the importance of tactile identity, a factor that is strongly related to the level of intimacy within a relationship. Since touch is not unidirectional, digital touch needs to be perceived by both partners during the remote tactile exchange. Participants talked of their need to have a sense of the feel of the skin that is touching them/being touched; that is, they wanted a sense of a bi-directional touch during the interaction. In family or romantic pairs, where a strong level of knowledge of each other exists, a sense of physical presence was personal, as it related to knowledge and experience of the physical identity or tactile experience of the 'other'. Participants expected that the temperature they felt would reflect the typical skin temperature of the person they know and considered it as a part of the conveyed tactile message to be interpreted. Other physical characteristics that could be captured and transferred through a remote touch system that contribute to identity included, for example, detecting the relative size of each other's body parts (the tiny hand of a child touching her bigger mother's hand). The body part size could be captured by the amount of area that one hand can touch at once or by the amount of strength that this could exert. Idiosyncratic tactile patterns also contributed to building a sense of tactile identity. This points to the potential benefits of touch technology devices/systems being customisable by users to accommodate the different ways that people touch (e.g., the location of touch and patterns, their own temperature). While studies have shown that participant-pairs develop a personal digital language over time through interaction with the resources and constraints offered to them by the technology (see for example [56]), this paper argues that it is also interesting to understand how idiosyncratic tactile language developed through digital remote tactile interactions transfers back to physical ones, when physical contact is possible.

\subsubsection{Presence/Identity vs Tactile message: a two-level communication process}

While in many cases, the sense of our presence/identity is itself the message that we want to send to the other; that is, "I'm here for you", the more 'complex' (e.g. emotional content) messages we aim to send through remote or physical touch work through the same modalities. This use of touch modalities thus raises the need to be able to distinguish between the work of interpreting a tactile message related to presence and identity and emotional content. A possible design solution would be to enable user-pairs to initially use the available haptic modalities to create a shared sense of presence and identity, and then to enable them to engage in sending, receiving and interpreting more complex messages. Such initial tactile exchanges could be used as a baseline for haptic sensations (e.g., a baseline of temperature, of pressure, of size, of speed, etc.) from which deviations that arise can then be used to characterize the meaning of the message and form the space for its interpretation. This would mean, for example, that a heat sensation used to show anger may be calibrated with respect to the skin temperature of the sender (the neutral point). Such baselines could be re-set during a long conversation to reflect change (e.g., the skin temperature increases because our hand has been warmed up by the warm messages of comfort we received), and to enable people to check if that baseline identity has changed thanks to our message of comfort.

\subsubsection{Sense of Control and Privacy}

Issues of control and privacy emerged as critical and somewhat inter-related in remote communication since the typical means to enact them are partially lost $[65,80]$. The study in VR [71] showed that the direction of initiation of touch (i.e., who in the dyad initiated touch) has a strong effect on a variety of emotions (e.g., anxiety, disgust, happiness). Our participants sought the possibility to explicitly control not just touch but also which haptic channels were left open for reception. This goes beyond suggestions from previous studies [65] where a button was available to ask permission for initiation of a tactile interaction. In addition to this level of modality control, our findings suggests that a presence/identity button could also be added to remote touch devices/systems to enable a person to shift their attention between the exchanged haptic properties that form the message back to the haptic properties that characterize presence and identity. This button would function to explicitly shift attention from what a person is telling (through touch) to one of feeling of presence and engagement with identity from the background to the foreground, as desired and needed. This possibility raises the question of the consequences and control of making visible such shifts in attention. Who should perceive what is in the foreground of the other person? In the context of physical touch, interactional and 
behavioural cues can indicate where one's attention is. Such cues could be incorporated into the automatic tactile responses that we send, when only the remote tactile channel is available. Furthermore, a critical question for digital touch technologies is to what extent a person should be allowed to control what is in the foreground of the receiver. This calls for further studies to address these questions as different contexts (e.g., co-workers, friends, romantic partners, carer-patients) may raise different needs as well as different ethical issues. Nonetheless, it suggests a need to consider how people bring attention to what matters to them through their use of touch during a conversation, e.g., using specific tactile gesture such as shaking or pressing the other person hands, or by suddenly removing our hand in protest. It would be interesting to investigate how such enabling/disabling transferring of identity information and attention shift could be used to solve such conflictual situations.

Privacy was an import dimension beyond issues of identity and was key to notions of control. The studies showed that various factors affected the level of tactile presence that was acceptable or desirable for both actors in the interaction, e.g., social and environmental contexts, types of relationship, and their affective state. Participants appreciated being able to switch haptic channels on and off, but they wanted more control on their right for privacy; in particular, how much, where and how they touched and were touched. Social rules typically control such decisions and in certain contexts a wrong action may lead to serious misunderstandings and consequences. Emotional states also emerged as factors affecting the desired level of privacy; that is the desire for touching and for being touched. Design implications emerge in relation to the perception and selection of the hand area to touch as discussed later in this section.

\section{Table 8: Key design requirements in relation to social dimensions of presence, identity and privacy}

\begin{tabular}{|c|c|c|}
\hline Social Tactile Dimensions & $\begin{array}{l}\text { Means of realizing these } \\
\text { dimensions }\end{array}$ & $\begin{array}{l}\text { Technology requirements needed } \\
\text { to realize these: }\end{array}$ \\
\hline Presence & $\begin{array}{l}\text { Sense of bidirectional touch } \\
\text { during interaction } \\
\text { Sense of past touch interaction } \\
\text { Levels of presence vs } \\
\text { presence/absence signal } \\
\text { Uncontrolled reactions (e.g. } \\
\text { flinching) to touch \& be touched }\end{array}$ & $\begin{array}{l}\text { Sense of feeling the other person's } \\
\text { skin and its changes in response } \\
\text { Sense of own skin responses (e.g. } \\
\text { sweat due to the hand-heat) } \\
\text { Control over amount of body and } \\
\text { area touched }\end{array}$ \\
\hline Identity & $\begin{array}{l}\text { Ownership of the body/hand } \\
\text { A person's idiosyncratic touch } \\
\text { characteristics } \\
\text { A person's tactile preferences }\end{array}$ & $\begin{array}{l}\text { Awareness of own skin temperature } \\
\text { Relatable to own body part (e.g. } \\
\text { hand) size } \\
\text { Idiosyncratic tactile patterns } \\
\text { Individual ways of touching }\end{array}$ \\
\hline $\begin{array}{l}\text { Two level communication } \\
\text { process: identity/present vs } \\
\text { emotional message }\end{array}$ & $\begin{array}{l}\text { Swapping content } \\
\text { foreground/background } \\
\text { attention }\end{array}$ & $\begin{array}{l}\text { Setting baseline of other person's } \\
\text { skin } \\
\text { Switch button between identity- } \\
\text { only/message content }\end{array}$ \\
\hline Sense of control and privacy & $\begin{array}{l}\text { Having control over being } \\
\text { touched } \\
\text { Controlling the body area that } \\
\text { can be touched } \\
\text { Being able to offer a body area to } \\
\text { be touched } \\
\text { Being able to send rejection sign }\end{array}$ & $\begin{array}{l}\text { Ability to block incoming touches or } \\
\text { modalities of it } \\
\text { Ability to send a rejection signal to } \\
\text { incoming touch } \\
\text { Ability to send an acceptance signal } \\
\text { to an incoming touch } \\
\text { Ability to offer a body area to } \\
\text { receive an incoming touch }\end{array}$ \\
\hline
\end{tabular}




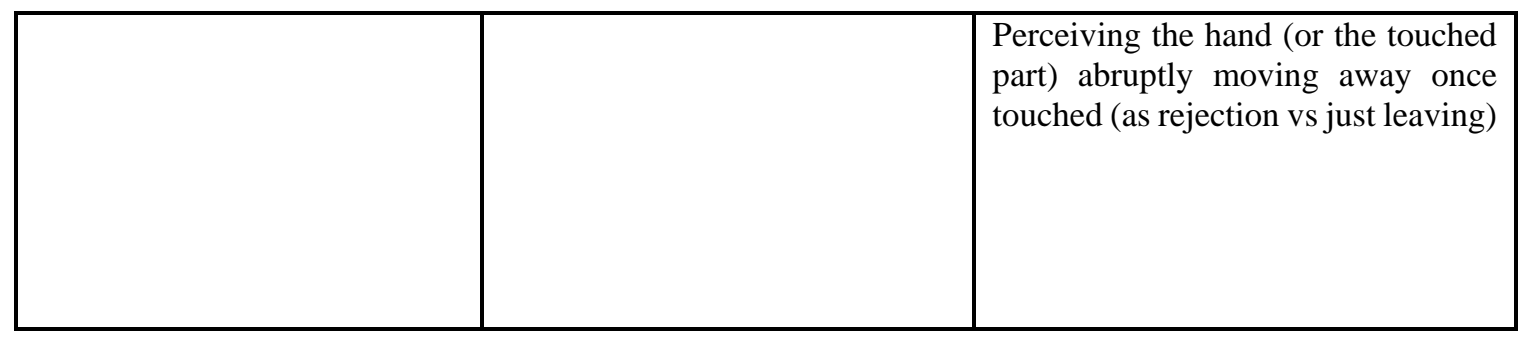

\subsection{Creation of emotional content}

While previous studies have focused on the existence of stereotypical emotional tactile patterns that can be interpreted outside of contexts [29] (see sections 2.2 and 2.3), our studies show that meanings generated around the main elements of touch messages, were largely personal, suggesting that when situated in specific contexts and relationships, they are less shaped by broadly agreed social norms and etiquettes of digital touch (which we envisage will change as they become domesticated), but rather draw on everyday personalized touch practices within a specific relationship (whilst acknowledging that even the most intimate of touches is socially and culturally shaped). Still, some interesting emotion-tactile patterns emerged in the use of modalities and how modalities were modulated and combined to form complex messages. In this section, we highlight key insights, first on the modalities and affective meanings (summarised in table 9), and second the patterns and dynamics of tactile interaction in relation to: speed, change, duration, and touch patterns, the localization and amount of touch, and body reactions as feedback (summarised in Table 10).

\subsubsection{Modalities and affective meanings}

Each modality investigated contributed to creating and interpreting emotional messages (see Table 9).

Pressure: Our results confirm the importance of pressure in human-human physical tactile interaction as shown in other studies on physical touch (e.g., [33,79]), and confirm the relationship between the pressure exerted or perceived during touch and the intensity of the specific emotional message communicated independently of its valence. In addition to its contribution to modulate the intensity of emotional messages, our studies show that in technology-mediated touch pressure helps to alleviate the physical distance between two interacting agents by enhancing their sense of presence, even after the interaction has ended, as a sense of pressure persists for some time after it has stopped being exerted.

Temperature: Heat, a less explored tactile modality, emerged as critical to both communicating emotion and providing a sense of presence and identity. Indeed, the limited attention to this modality both in humanhuman tactile interaction and in technology mediated tactile interaction is surprising given that the skin is rich in temperature receptors [68] and the warmth of the body is known to contribute to bonding [9]. Heat has been used less but its importance as a social sign in the context of technology-mediated tactile interaction is highlighted in [74], defining it as critical for perceiving and interpreting touch. For example, a robot can change its skin temperature to communicate stereotypical emotions [79]. However, in human-human interaction the warmth (temperature) that comes with touching is due to the temperature of the skin and cannot be controlled by the sender except by avoiding touch. Beyond its use to modulate the meaning and valence of affective messages, temperature was perceived by receivers as an amplifier of the overall emotional experience of being touched, and of the message itself. Warm was used for, and perceived to communicate, a feeling of comfort in pain, support, empathy, love. In contrast, cold was generally used to create a feeling of distance or rejection while heat was often used to convey anger.

Vibration: Differently from pressure and heat, vibration was described as unnatural and unpleasant and was rarely used by study participants in this study's scenarios. This finding is pertinent as vibration is possibly currently the most used tactile modality in commercial tactile distance communication technology [19,55]. Still, despite participants finding it more difficult to connect vibration to aspects of 'natural' touch, it nevertheless played a role in building digital tactile exchanges especially in conveying increased arousal. Since vibration does not form the basis of physical social touch, it worked as a mechanism to reflect associated familiar sentiments (e.g., excitement, reassurance), touches (tickling, stroking) and impact of 
touch (e.g., capturing attention). Beyond communicating high levels of excitement (possibly as a form of intense playfulness), its other frequent use was to indicate rejection because of its unpleasant feeling. Thus, vibration may provide a new form of 'social' tactile sensation and has the potential to elicit wider meaning sets through its ambiguous mapping. In addition, it shows that tactile experiences that are not directly mapped to our physical touch experiences can play an effective role in communication. However, these need to be investigated further rather than simply used as a replacement for physical touch, as is currently the case in most devices for remote touch.

Sound: Beyond these more typical modalities that can be directly related to physical touch, sound emerged as an interesting augmentation of touch. Although touch is generally not described in terms of sound and few types of touch would generate a clearly associated sound (a slap), people thought that emotion-related sounds could enhance the perception of the affective meaning of a tactile message when context is ambiguous and touch is the only available information. However, while sound may provide another modality for enhancing tactile communication, it would need to be carefully studied as it can affect not only the interpretation of the message but also the perception of the surface touched (in this case the skin of the partner). In other studies it was shown that the type of sound played during a tactile interaction with a surface changed the perception of the surface touched [72]. In the project Emotion walking [6], for example, researchers were able to change the perceived type of floor a person was walking on by changing the sound of the footsteps. Since metaphorical sound can be used to alter the perception of a gesture (e.g., its lightness or heaviness) and the length or duration of it [67], sound could be used to overcome the limitation of technology in controlling the granularity of the transmitted sensations as well as the amount of area covered by the gesture.

\section{Table 9: Modalities and affective meanings}

\begin{tabular}{|c|c|c|c|}
\hline $\begin{array}{l}\text { Physical dimensions of } \\
\text { tactile interaction with } \\
\text { system } \\
\text { (Modalities) }\end{array}$ & $\begin{array}{l}\text { Affective meanings } \\
\text { realized } \\
\text { through/associated with } \\
\text { the dimension }\end{array}$ & Context creation & $\begin{array}{l}\text { 'Naturalness' } \\
\text { (i.e. comparison to } \\
\text { real touch) }\end{array}$ \\
\hline Pressure & $\begin{array}{l}\text { Gives meaning in most } \\
\text { of the affective states } \\
\text { explored in study } \\
\text { It also modulates arousal }\end{array}$ & $\begin{array}{l}\text { Sense of presence } \\
\text { Sense of skin } \\
\text { touching }\end{array}$ & $\begin{array}{l}\text { Essential as no sense } \\
\text { of touch was felt } \\
\text { without some } \\
\text { pressure }\end{array}$ \\
\hline Temperature & $\begin{array}{l}\text { Gives meaning in most } \\
\text { of the affective states } \\
\text { explored in study } \\
\text { Emotional amplification } \\
\text { It also modulates valence } \\
\text { Metaphorical mapping } \\
\text { between emotion and } \\
\text { temperature }\end{array}$ & $\begin{array}{l}\text { Identity } \\
\text { Sense of skin } \\
\text { touching } \\
\text { Receiver } \\
\text { temperature } \\
\text { preferences }\end{array}$ & $\begin{array}{l}\text { Skin temperature } \\
\text { Expectation and } \\
\text { awareness of each } \\
\text { other's temperature } \\
\text { and each other's } \\
\text { environment }\end{array}$ \\
\hline Vibration & $\begin{array}{l}\text { This dimension increased } \\
\text { arousal, Unpleasant state }\end{array}$ & $\begin{array}{l}\text { Extend physical } \\
\text { touch }\end{array}$ & $\begin{array}{l}\text { Mainly unnatural, } \\
\text { unpleasant }\end{array}$ \\
\hline Sound & $\begin{array}{l}\text { Suggested: most } \\
\text { affective states according } \\
\text { to metaphorical meaning } \\
\text { or sound characteristics }\end{array}$ & $\begin{array}{l}\text { Extend physical } \\
\text { touch gestures } \\
\text { Affective modality } \\
\text { Can alter the } \\
\text { perception of other } \\
\text { modalities (e.g., } \\
\text { lighter, vs heavier, } \\
\text { longer vs shorter) }\end{array}$ & $\begin{array}{l}\text { Manly unnatural, but } \\
\text { augments human } \\
\text { touch }\end{array}$ \\
\hline
\end{tabular}


In summary, the studies revealed differential responses to each modality (referenced in physical or emotive terms), opening opportunities to newly integrate the physical and affective aspects of communication. Participants demonstrated this by bringing in their own meanings and touch practices, suggesting the malleability of digital touch communication. Findings also suggest that mediated touch need not replicate physical touch, but rather specific touch practices may change through evolving integration of affective notions of warmth, with pressure or vibration. Rather than the system providing a fixed set of touches, the flexibility of using haptic sensations for generating messages enabled participants to explore digital 'tactile meanings'. The complex tactile dialogues that participants created through the TE system in these two studies shows how digitally mediated touch extends beyond the mapping of haptic sensation-emotions to the use of remote touch to build nuanced emotional dialogues.

7.2.2 Dynamics of tactile interaction and affective meanings: speed, change, duration, touch patterns

Previous studies on tactile interactions have shown how affective messages are modulated by the kinematics of the tactile gesture. Speed, duration, direction and frequency have been identified as the main kinematic dimensions that help create and discriminate between emotional meanings of touch (e.g., [2,24,53,63]). While it was possible to set different levels of intensity in terms of pressure, temperature and vibration in the TE devices, our results suggest the need for finer control of such dimensions to modulate emotional messages and create more complex messages. As we are witnessing advances on the type of kinematics patterns produced and the intensity and temporal granularity offered by haptic technology (see section 2.2.), it becomes increasingly important to understand the opportunity that such finer control offers to the creation of messages and develop more comprehensive evaluation metrics. At the time of writing, advancements in haptic technology are mainly evaluated for precision, pleasantness, and set of stereotypical emotions and gestures possible (e.g., [3,39, 51, 61, 64]). Our findings contribute to understanding of the dynamics of tactile interaction and affective meanings (see Table 10).

Speed of activation and granularity of change: First of all, the speed of activation and changes in intensity (e.g., temperature/pressure) were considered 'unnatural' and too slow in our devices. This slow speed of change reduced the level of synchrony between sender and receiver and could lead to a sense of incongruence if the tactile system was used in combination with other forms of communication, such as audio or video. Slow changes were generally associated with positive valence and low arousal emotional states. Quick changes in exerted amount of pressure or change in temperature were critical to building a sense of high arousal, especially during negatively valenced tactile messages. Slight differences in amount of heat and pressure, for example, changed a message from signifying affection to anger. The speed of activation emerged as a way to combine different levels of a modality or different modalities to form complex messages, as briefly described below.

Duration and intensity: As in other studies [33,53] duration, intensity and repetition of haptic sensations were mechanisms used to create more nuanced message designs that are important for expressivity. Here, the 'high' levels (of all dimensions) were found to be central to conveying impactful affective messages: 'high' being associated with intensity of emotion. However, differential use of these mechanisms produced various patterns of sensation, each generating different meanings across participants. Although participants might agree on the meaning they attribute to some properties of touch (e.g., vibration as cheerful), other nuances generate variations in meaning that are critical for communication.

Table 10: Dynamics of tactile interaction and affective meanings

\begin{tabular}{|l|l|l|}
\hline Dynamics of modalities & $\begin{array}{l}\text { Affective meaning } \\
\text { Realized through/associated } \\
\text { with the dynamic }\end{array}$ & $\begin{array}{l}\text { Naturalness (match to real } \\
\text { touch) }\end{array}$ \\
\hline $\begin{array}{l}\text { Speed of activation } \\
\text { (incremental vs sudden) }\end{array}$ & $\begin{array}{l}\text { Modulate both arousal and } \\
\text { valence of affective state }\end{array}$ & $\begin{array}{l}\text { Perceived as awkward unless } \\
\text { within the natural range of } \\
\text { speed of activation }\end{array}$ \\
\hline
\end{tabular}




\begin{tabular}{|l|l|l|}
\hline $\begin{array}{l}\text { Granularity of changes } \\
\text { (incremental vs sudden) }\end{array}$ & $\begin{array}{l}\text { Critical to control emotional } \\
\text { meaning }\end{array}$ & $\begin{array}{l}\text { Conforming to social norms of } \\
\text { touch }\end{array}$ \\
\hline Duration \& Intensity & Enhance emotional nuance & $\begin{array}{l}\text { Perceived as awkward unless } \\
\text { within the natural range and not } \\
\text { painful }\end{array}$ \\
\hline $\begin{array}{l}\text { Touch patterns } \\
\text { (e.g. still, repetitive, cyclic } \\
\text { alternation, random) }\end{array}$ & To modulate levels of arousal & To echo tactile gestures \\
\hline $\begin{array}{l}\text { Localization \& amount of } \\
\text { touch } \\
\text { (including place, area } \\
\text { touched, direction of touch, } \\
\text { palm center vs periphery, top } \\
\text { vs bottom, fingers, sender vs } \\
\text { receiver hands) }\end{array}$ & $\begin{array}{l}\text { Level of intimacy } \\
\text { Social context }\end{array}$ & $\begin{array}{l}\text { Reflective of the type of } \\
\text { relationship and/or social } \\
\text { context of touch } \\
\text { Expectation of where touch } \\
\text { sent is perceived given the } \\
\text { gesture }\end{array}$ \\
\hline Body reactions as feedback & $\begin{array}{l}\text { Solving ambiguity through } \\
\text { interpretation } \\
\text { Enabling building } \\
\text { knowledge of the other }\end{array}$ & $\begin{array}{l}\text { Using feedback (automatic and } \\
\text { construed) to reinforce } \\
\text { understanding }\end{array}$ \\
\hline
\end{tabular}

Touch patterns included stillness, repetition, and cyclical alternation and randomness.

Still gestures were used especially in the context of low arousal to convey support, love, or a sense of relaxing. The lack of tactile motion, beyond the initiation of the tactile gesture, often aimed to reduce the sense of intrusion or provide a sense of quietness and/or simple presence.

A repetitive pattern (rather than a single touch) was critical to simulate particular touch gestures, such as caresses that are inherently cyclic, and a sense of excitement.

Cyclic alternation and randomness also emerged in creating dynamic patterns. Alternation of extreme changes in one modality aimed to reflect a form of punishment through distress from the quick change to the opposite sensation. Randomness aimed to create distress or playfulness due to its unpredictability. Unpredictability was also obtained by randomly switching between modality combinations rather than opposite sensation of the same modality. Even in the context of patterns the speed of activation and change was considered important to modulate the emotional content of the same pattern and to ensure that it was perceived as natural.

The ability to repeatedly and quickly press buttons to heighten the tactile experience illustrates how the technology affordances can generate new designs of touch sensations to convey meaning in each specific context. However, all participants highlighted the need for better clarity of distinction across the levels within each of the above actuation methods: in particular, enlarging the scope of temperature and pressure, clarifying the distinction between the highest and lowest levels; and increasing the response speed to allow changes to be clearly felt.

\subsubsection{Dynamics of tactile interaction and affective meanings: Localization and the amount of touch}

Finally, our results suggest that not only do the kinematic and types of gesture matter for the affective message but also the amount and part of surface touched (mainly the hand in our case); that is differences in touch locality across the hand. In the case of loneliness, for example, participants used gestures that either avoided touching or touched just a very small area of the other person's hand. In contrast, when expressing ecstasy or longing, participants tried to use larger surface areas, wanting to move beyond the hand to the forearm. Designing for mediated touch should, therefore, enable digital touch to contact different amounts of the hand and beyond to other parts of the body, if socially allowed, and consider how the specific touch may differ as a result. 
As discussed in the literature, most HCI studies treat touch primarily as a uniform feeling over a body part while psychology research on touch has mainly focused on understanding how different body parts (e.g. shoulder vs hand) are selected to convey or interpret affective messages [33]. Our work provides a complex picture of how the body part contributes to the creation and interpretation of tactile messages. When designing for technology-mediated touch, our findings suggest that the system should allow the sender to choose the area of the hand to touch and how to touch it. These findings also raise the need for haptic sensations that are well localized when this differentiation matters. Evaluation studies on technology advancements from this perspective could hence consider not only if the sensation is perceived in the specific point, but also the different areas to be investigated and how their sensitivity may alter the message of the haptic sensation delivered. Here, we contribute some of our understanding for the hands, and argue that similar investigations could usefully be extended to other body parts.

Skin sensitivity level: Participants highlighted how they built tactile messages by considering the different levels of skin sensitivity of the hand. Messages were built by selecting the specific areas to be touched to ensure that the right level of tactile intensity was perceived. This is in line with studies in neurophysiology showing how our skin sensitivity changes according to the type and density of tactile receptors innervating the specific skin area. Early studies [42] show that even different regions of the glabrous skin of the hand present different densities of highly sensitive receptors with the overall distribution increasing in the proximal-distal direction: with a slight increase from the palm to the main part of the fingers and with a sudden stronger change in distribution between the main part of the fingers and the fingertips. The importance of being able to select the areas of the hand to touch emerges from the physiology of the skin but also the social meanings that are attached to those areas.

Palm centre vs periphery: As in [53], our participants perceived the palm as the most intimate zone of the hand and as such should only be touched if such intimacy is wanted or allowed. However, differently from [39], the direction of movement towards or away from the palm contributed to maintaining the level of intimacy desired and acceptable in that moment, rather than simply giving a valence to the exchange message. Fingers: The finger area emerged as particularly important, not only as a way to reduce intimacy but also to reduce privacy invasion. For example, during sad moments, touching just the fingers and not the palm was a way to leave space for the receiver during a difficult moment. However, differently from what was suggested in [41] no specific valence was associated with different fingers.

Palm top vs bottom: The differentiation between the back of the hand and the palm also clearly contributed to the building of different meanings. Touching the top of the other person's palm was more about a one-way message or setting some hierarchy in the emotional situation (e.g. putting a hand on the top of the other to say I'm here to support you), while touching each other's palms was more about sharing.

Gesture affordance: Finally, the importance of effect of locality over the top of the hand emerged in relation to the shape of the tactile gesture and possibly its affordance. While the TE system operated pressure solely on the top of the other person's hand, people talked about how each different type of touch needs to be created by and felt on different parts of the hand. A clear example emerged in relation to the sense of pressure exerted and perceived during hand holding or grabbing attempts. The feeling of holding hands achieved through the palm of the sender placed on top of the hand of the receiver was perceived as unnatural. Rather, participants expected that pressure originating from the fingertips (possibly requiring less effort to produce that sense of pressure that the palm) would be felt on the two sides of (or possibly opposite sides of) the receiver's hand. This finding suggests the need for the system to allow a change in the position of the hand for both the sender and receiver and ensure that such a position is perceived during the touch interaction.

Sender vs receiver hands position: The TE design denotes that the hands of both people would be placed in the same way; however, even if hands were placed in the same direction and place, hands of different sizes sat differently in the devices. Thus, hand-size led to participants perceiving the same haptic implementation differently. It is therefore important to consider position and hand-rescaling when both simulating, sending and receiving a message. In addition, to ensure that one is conforming to social rules of touch it is critical that the sender is able to perceive the hand shape or body part of the receiver that the system is designed for. Receivers also raised the need to modulate the tactile message they received, beyond just switching channels 
on and off. While this was partially possible by exposing only part of the hand to the TE, the sender should be able to receive such information to understand the privacy needs of the receiver.

\subsubsection{Dynamics of tactile interaction and affective meanings: Body reactions as feedback}

As tactile interaction emerged as intrinsically ambiguous, a key emergent aspect of the communication process relates to 'feedback', not only in terms of what tactile message was sent but also how the other person involuntarily reacted to it. Non-digital touch communication involves 'touching and being touched' [50]. In the digital context this is important for understanding whether a tactile message has fulfilled its purpose, and in shaping continued reciprocal tactile communication. This suggests mediated touch devices should be synchronous in the way that they reproduce sensations and allow users to differentiate whether the touch pattern conveys the emotion of the sender or the emotion the sender wants the receiver to feel.

The feedback response becomes critical to help people learn about each other's preferences. Our participants used what they were learning about the other person to shape the valence of the tactile message. (Warm or cold temperature were, for example, selected to create positive or negative emotions according to the thermal sensation the receiver was thought to like.) Such a learning process is important over long-term relationships and can occur from reading involuntary responses as people get to know each other better, but also during short term situations where the pleasure of the sensation may be affected by the temperature in the room, by their physical states or their mood. Hence, from a technology perspective, the question is: what form should the feedback take? Whilst the feedback could be a crafted tactile feedback using the same set of modalities available to send the message, subtler and more purposely designed feedback may be necessary. For example, a feeling of embarrassment when we are touched could result in a simple tremble of the hand or a very slow retraction; or a pleasurable response to a romantic touch could result in moving the hand even closer to the other; a response of surprise or displeasure may lead to the hand very quickly disappearing and possibly reconnecting in the case of surprise but not in the case of displeasure. Hence, it is necessary to consider the modalities needed to capture such responses and feed them back. A TE system could be embedded with sensors that are able to capture such involuntary responses by sensing the hand leaving the device and the speed at which it leaves, or by sensing the trembling and converting such information into feedback in the original message's sender. A subsequent question is whether users want to give away what we feel or be more in control of what is conveyed from their involuntary responses.

\subsection{Limitations}

Some limitations that may have affected the research outcomes are worthy of mention. Firstly, the system design itself inevitably shapes the specific haptic sensations that can be produced and sent, not only in terms of their individual properties, but also in combination with one another. Some design issues outlined above (e.g. distinguishing temperature from natural warmth of the hand, and the noise from the pressure pump), may also have affected both the use and interpretation of tactile messages. Inevitably this limitation constrains the generalizability of the findings and highlights the challenges of work such as this. Given that our study is precisely concerned with how technologies shape the use and interpretation of tactile messaging we see this limitation as an inevitable and contextual aspect of research. Secondly, while the small sample sizes used in each study context raise questions around representativeness, this approach enabled in-depth qualitative research on affective touch communication and the role of digital touch properties in this process. Thirdly, a technical limitation of the study is that the TE system used linear resonant actuators to deliver the vibration feedback which limited the output to one frequency, further work on the potential of vibration for making meaning through dyadic haptic affective touch using vibrotactile actuators that allow independent specification of frequency and amplitude is needed. While participants' negative reactions to vibration may have been due to the type of technology used, the studies nevertheless raise the important issue that vibration is not considered a natural sensation in human touch communication. This highlights the need for careful design consideration, particularly around how the level of pleasantness will contribute to appropriation and creating meaning, rather than expecting to simply create a sense of connection. Finally, while we designed the work to engage with different emotional contexts and situations, implementation limitations meant that the study context was still artificial to some extent, in contrast to studying meaning making in everyday 
situations outside of the laboratory. However, it is currently hard to conceive of studies in everyday environments given the context of the (often unstable) prototype touch devices that typify the current technological landscape of remote touch. These. Further work should build on this by engaging more participants in contexts outside the lab.

\section{Conclusion}

This work contributes to the body of knowledge on how remote touch can be conveyed. Multiple dyads relationships, contexts and perspectives were explored to build a broader understanding of how tactile messages were created and interpreted, and the factors that affected such processes were identified. The design of the TE provided a research tool that enabled exploration of how meaning is generated around touch communication, when mediated by technology (using vibration, pressure and temperature), and how common understanding and aspects of context and ambiguity are addressed and exploited in the creation and interpretation of touch messages. Using the TE system as an exploratory research tool, we explored the use of different modalities to create remote tactile exchanges to inform understanding of the design requirements for technology-mediated touch. While the emergence of a personal tactile language has been observed in Park et al [56], this study contributes by showing the meaning making processes that underlie their use across different communicative contexts, relationship types and modalities. We found that participants were able to create, send and interpret tactile messages, despite the complexity of the system and the scenarios. The two studies reported here suggest a number of design considerations as well as the need to rethink the TE advancement evaluation criteria, which aim at harnessing the fluid and emergent properties of touch communication. Overall, they suggest the importance of providing users with tools that allow them to customize and integrate their own shared meanings and understandings and situate them in context - rather than a set of predefined touch-icon gestures, a technology design could create gestures and allow the use of other people's sensation preferences to build tactile messages. A further critical consideration is to provide the possibility to touch and use different body areas - as a complex area with different regions and levels of sensitivity that differently contribute to touch meaning making, not only according to relationship distance, but also to perceived acceptability determined by the specific emotion (relationship and context). The work provides an in depth understanding of how digital presence, identity (within relationships) and control/privacy can be enriched or enhanced and the needs for a dual communication process of background information and of emotional content. This contributes to a new problem space, where the emphasis in digital touch communication shifts from generating 'recognizable touches' to providing tools that allow people to determine their touches and establish a common understanding about their meaning.

\section{ACKNOWLEDGMENTS}

This research was undertaken with funding from the UCL Social Science+ award; and as a part of the InTouch project, a European Research Council Consolidator Award (Award Number: 681489), and EPSRC Programme grant Embodied Intelligence (EP/V000748/1) - From Sensing to Collaboration: Engineering, Exploring and Exploiting the Building Blocks of Embodied Intelligence. We thank all the participants who took part in the studies and design workshops.

\section{REFERENCES}

[1] Rebecca Andreasson, Beatrice Alenljung, Erik Billing, and Robert Lowe. 2018. Affective Touch in Human-Robot Interaction: Conveying Emotion to the Nao Robot. Int. J. Soc. Robot. 10, 4 (September 2018), 473-491. DOI:https://doi.org/10.1007/s12369-017-0446-3

[2] Jeremy N. Bailenson, Nick Yee, Scott Brave, Dan Merget, and David Koslow. 2007. Virtual Interpersonal Touch: Expressing and Recognizing Emotions Through Haptic Devices. HumanComputer Interact. 22, 3 (August 2007), 325-353. DOI:https://doi.org/10.1080/07370020701493509

[3] Mathew. A. Baumann, Karon E. MacLean, Thomas W. Hazelton, and Ashley McKay. 2010. Emulating human attention-getting practices with wearable haptics. In IEEE Haptics Symposium. 
[4] Christopher C. Berger, Mar Gonzalez-Franco, Eyal Ofek, and Ken Hinckley. 2018. The uncanny $\begin{array}{lllllll}\text { valley of haptics. Sci. Robot. 3, } 17 \text { (April 2018), eaar7010. } & \end{array}$ DOI:https://doi.org/10.1126/scirobotics.aar7010

[5] Virginia Braun and Victoria Clarke. 2012. Thematic analysis. In APA handbook of research methods in psychology, Vol. 2. Research designs: Quantitative, qualitative, neuropsychological, and biological, H. Cooper, P.M. Camic, D.L. Long, A.T. Panter, D. Rindskopf and K.J. Sher (eds.). American Psychological Association, Washington, DC, US, 57-71.

[6] Roberto Bresin, Anna deWitt, Stefano Papetti, Marco Civolani, and Federico Fontana. 2010. Expressive sonification of footstep sounds. In Proceedings of the Interaction Sonification workshop, Stockholm, Sweden: KTH Royal Institute of Technology, 51-54.

[7] Michael Bull, Paul Gilroy, David Howes, and Douglas Kahn. 2006. Introducing Sensory Studies. Senses Soc. 1, 1 (March 2006), 5-7. DOI:https://doi.org/10.2752/174589206778055655

[8] Antonio Camurri, Giovanni De Poli, Anders Friberg, Marc Leman, and Gualtiero Volpe. 2005. The MEGA Project: Analysis and Synthesis of Multisensory Expressive Gesture in Performing Art Applications. J. New Music Res. 34, 1 (March 2005), 5-21. DOI:https://doi.org/10.1080/09298210500123895

[9] B. Candy. 2019. Keeping Virtual Reality Environments Harassment Free. Retrieved September 18, 2019 from https://onezero.medium.com/keeping-virtual-reality-environments-harassment-free$3 b 9 d 4 e 5 d 3416$.

[10] Chun-Yi Chen, Jodi Forlizzi, and Pamela Jennings. 2006. ComSlipper: an expressive design to support awareness and availability. In $\mathrm{CHI}$ ' 06 extended abstracts on Human factors in computing systems - CHI EA '06, ACM Press, Montr\&\#233;al, Qu\&\#233;bec, Canada, 369. DOI:https://doi.org/10.1145/1125451.1125531

[11] Constance Classen. 2012. The Deepest Sense. A Cultural History of Touch. University of Illinois Press, Urbana, Chicago and Springfield.

[12] Karen Collins and Bill Kapralos. 2019. Pseudo-haptics: leveraging cross-modal perception in

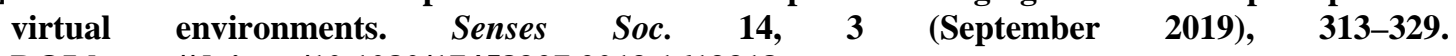
DOI:https://doi.org/10.1080/17458927.2019.1619318

[13] Anne Cranny-Francis. 2011. Semefulness: a social semiotics of touch. Soc. Semiot. 21, 4 (September 2011), 463-481. DOI:https://doi.org/10.1080/10350330.2011.591993

[14] Anik Debrot, Dominik Schoebi, Meinrad Perrez, and Andrea B. Horn. 2013. Touch as an Interpersonal Emotion Regulation Process in Couples' Daily Lives: The Mediating Role of Psychological Intimacy. Pers. Soc. Psychol. Bull. 39, 10 (October 2013), 1373-1385. DOI:https://doi.org/10.1177/0146167213497592

[15] Kelly Dobson, dana boyd, Wendy Ju, Judith Donath, and Hiroshi Ishii. 2001. Creating Visceral Personal and Social Interactions in Mediated Spaces. In CHI '01 Extended Abstracts on Human Factors in Computing Systems, 151-152.

[16] Robin Dunbar. 1996. Grooming, Gossip and the Evolution of Language. Faber and Faber.

[17]Elisabeth Eichhorn, Reto Wettach, and Eva Hornecker. 2008. A Stroking Device for Spatially Separated Couples. In Proceedings of the 10th International Conference on Human Computer Interaction with Mobile Devices and Services (MobileHCI '08), ACM, New York, NY, USA, 303306. DOI:https://doi.org/10.1145/1409240.1409274 
[18] Jan B. F. van Erp and Alexander Toet. 2013. How to Touch Humans: Guidelines for Social Agents and Robots That Can Touch. In 2013 Humaine Association Conference on Affective Computing and Intelligent Interaction, IEEE, Geneva, Switzerland, 780-785. DOI:https://doi.org/10.1109/ACII.2013.145

[19] Jan B. F. van Erp and Alexander Toet. 2015. Social Touch in Human-Computer Interaction. Front. Digit. Humanit. 2, (2015), 2. DOI:https://doi.org/10.3389/fdigh.2015.00002

[20] Tiffany Field. 2003. Touch. MIT Press, Massachusetts.

[21] Kory Floyd. 2000. Affectionate same-sex touch: the influence ofhomophobia on observers' perceptions. J. Soc. Psychol. 140, 6 (2000), 774-788.

[22] Bryan Fuller, Marcia J Simmering, Laura E Marler, Susie S Cox, Rebecca J Bennett, and Robin A Cheramie. 2011. Exploring touch as a positive workplace behavior. Hum. Relat. 64, 2 (February 2011), 231-256. DOI:https://doi.org/10.1177/0018726710377931

[23] Alberto Gallace and Charles Spence. 2010. The science of interpersonal touch: An overview. $\begin{array}{lllll}\text { Neurosci. Biobehav. Rev. 34, } 2 & \text { (February 2010), 246-259. }\end{array}$ DOI:https://doi.org/10.1016/j.neubiorev.2008.10.004

[24] Yuan Gao, Nadia Bianchi-Berthouze, and Hongying Meng. 2012. What Does Touch Tell Us about Emotions in Touchscreen-Based Gameplay? ACM Trans. Comput.-Hum. Interact. 19, 4 (December 2012), 1-30. DOI:https://doi.org/10.1145/2395131.2395138

[25] Daniel Gooch and Leon Watts. YourGloves, hothands and hotmits: devices to hold hands at a distance. 10.

[26] M. Melissa Gross, Elizabeth A. Crane, and Barbara L. Fredrickson. 2010. Methodology for Assessing Bodily Expression of Emotion. J. Nonverbal Behav. 34, 4 (December 2010), 223-248. DOI:https://doi.org/10.1007/s10919-010-0094-x

[27] Andrew K. Gulledge, Michelle H. Gulledge, and Robert F. Stahmannn. 2003. Romantic Physical Affection Types and Relationship Satisfaction. Am. J. Fam. Ther. 31, 4 (July 2003), 233-242. DOI:https://doi.org/10.1080/01926180390201936

[28] S. Gumtau. 2005. Tactile semiotics: the meanings of touch explored with low-tech prototypes. In First Joint Eurohaptics Conference and Symposium on Haptic Interfaces for Virtual Environment and Teleoperator Systems. World Haptics Conference, 651-652. DOI:https://doi.org/10.1109/WHC.2005.124

[29] Antal Haans. 2007. Investigating Response Similarities between Real and Mediated Social Touch: A First Test. (2007), 6.

[30] Antal Haans and Wijnand IJsselsteijn. 2006. Mediated social touch: a review of current research and future directions. Virtual Real. 9, 2-3 (January 2006), 149-159. DOI:https://doi.org/10.1007/s10055-005-0014-2

[31] Marc Hassenzahl, Stephanie Heidecker, Kai Eckoldt, Sarah Diefenbach, and Uwe Hillmann. 2012. All You Need is Love: Current Strategies of Mediating Intimate Relationships through Technology. ACM Trans. Comput.-Hum. Interact. 19, 4 (December 2012), 1-19. DOI:https://doi.org/10.1145/2395131.2395137

[32] Matthew J. Hertenstein. 2002. Touch: Its Communicative Functions in Infancy. Hum. Dev. 45, 2 (2002), 70-94. DOI:https://doi.org/10.1159/000048154 
[33] Matthew J. Hertenstein, Rachel Holmes, Margaret McCullough, and Dacher Keltner. 2009. The communication of emotion via touch. Emotion 9, 4 (2009), 566-573. DOI:https://doi.org/10.1037/a0016108

[34] Richard Heslin, Tuan D. Nguyen, and Michele L. Nguyen. 1983. Meaning of touch: The case of touch from a stranger or same sex person. J. Nonverbal Behav. 7, 3 (1983), 147-157. DOI:https://doi.org/10.1007/BF00986945

[35] Gijs Huisman. 2012. A touch of affect: mediated social touch and affect. In Proceedings of the 14th ACM international conference on Multimodal interaction - ICMI '12, ACM Press, Santa Monica, California, USA, 317. DOI:https://doi.org/10.1145/2388676.2388746

[36] Gijs Huisman. 2017. Social Touch Technology: A Survey of Haptic Technology for Social Touch. IEEE Trans. Haptics 10, 3 (July 2017), 391-408. DOI:https://doi.org/10.1109/TOH.2017.2650221

[37] Gijs Huisman and Aduén Darriba Frederiks. 2013. Towards tactile expressions of emotion through mediated touch. In CHI '13 Extended Abstracts on Human Factors in Computing Systems on - CHI EA '13, ACM Press, Paris, France, 1575. DOI:https://doi.org/10.1145/2468356.2468638

[38] Gijs Huisman, Aduén Darriba Frederiks, Jan B. F. van Erp, and Dirk K. J. Heylen. 2016. Simulating Affective Touch: Using a Vibrotactile Array to Generate Pleasant Stroking Sensations. In Haptics: Perception, Devices, Control, and Applications, Fernando Bello, Hiroyuki Kajimoto and Yon Visell (eds.). Springer International Publishing, Cham, 240-250. DOI:https://doi.org/10.1007/978-3-319-42324-1_24

[39] Alexandra Ion, Edward Jay Wang, and Patrick Baudisch. 2015. SkinDragDisplays:Dragging a Physical Tactor Across the User's Skin Produces a Stronger Tactile Stimulus than Vibrotactile. In 33rd Annual ACM Conference on Human Factors in Computing Systems (CHI'15), New York, NY, USA, 2501-2504. DOI:http://dx.doi.org/10.1145/2702123.2702459

[40] Brittany K. Jakubiak and Brooke C. Feeney. 2017. Affectionate Touch to Promote Relational, Psychological, and Physical Well-Being in Adulthood: A Theoretical Model and Review of the Research. Personal. Soc. Psychol. Rev. 21, 3 (August 2017), 228-252. DOI:https://doi.org/10.1177/1088868316650307

[41] Carey Jewitt and Kerstin Leder Mackley. 2019. Methodological dialogues across multimodality and sensory ethnography: digital touch communication. Qual. Res. 19, 1 (February 2019), 90-110. DOI:https://doi.org/10.1177/1468794118796992

[42] Roland S. Johansson and A.B. Vallbo. 1979. Tactile sensibility in the human hand: relative and absolute densities of four types of mechanoreceptive units in glabrous skin. J. Physiol. 1, (1979), 283-300.

[43] Lawrence H. Kim and Sean Follmer. 2019. SwarmHaptics: Haptic Display with Swarm Robots. In Proceedings of the 2019 CHI Conference on Human Factors in Computing Systems., Association for Computing Machinery, New York, NY, USA, Paper 688, 1-13. DOI:https://doi.org/10.1145/3290605.3300918

[44] Andrea Kleinsmith and Nadia Bianchi-Berthouze. 2013. Affective Body Expression Perception and Recognition: A Survey. IEEE Trans. Affect. Comput. 4, 1 (March 2013), 15-33. DOI:https://doi.org/10.1109/T-AFFC.2012.16

[45] Aradhna Krishna (Ed.). 2010. Sensory Marketing. Research on the Sensuality of Products. Routlege, New York.

[46] Rudolf Laban and Lisa Ulman. 1988. The mastery of movement. Northcote House, Plymouth, England. 
[47] Josephine W. Lee and Laura K. Guerrero. 2001. Types of touch in cross-sex relationships between coworkers: perceptions of relational and emotional messages, inappropriateness, and sexual harassment. J. Appl. Commun. Res. 29, 3 (January 2001), 197-220. DOI:https://doi.org/10.1080/00909880128110

[48] Kathleen C. Light, Karen M. Grewen, and Janet A. Amico. 2005. More frequent partner hugs and higher oxytocin levels are linked to lower blood pressure and heart rate in premenopausal women. Biol. Psychol. 69, 1 (April 2005), 5-21. DOI:https://doi.org/10.1016/j.biopsycho.2004.11.002

[49] Mike McLinden and Stephen McCall. 2002. Learning through Touch: Supporting children with visual impairement and additional difficulties. David Fulton Publsihers Ltd.

[50] Maurice Merleau-Ponty. 2012. Phenomenology of Perception. Routlege, London; New York.

[51] Sachith Muthukumarana, Samitha Don Elvitigala, Juan Pablo Forero Cortes, Denys J.C. Matthies, and Suranga Nanayakkara. 2020. Touch me Gently: Recreating the Perception of Touch using a Shape-Memory Alloy Matrix. In Proceedings of the 2020 CHI Conference on Human Factors in Computing Systems (CHI '20)., Association for Computing Machinery, New York, NY, USA, 1-12. DOI:https://doi.org/10.1145/3313831.3376491

[52] Carman Neustaedter and Saul Greenberg. 2012. Intimacy in long-distance relationships over video chat. In Proceedings of the 2012 ACM annual conference on Human Factors in Computing Systems - CHI '12, ACM Press, Austin, Texas, USA, 753. DOI:https://doi.org/10.1145/2207676.2207785

[53] Marianna Obrist, Sriram Subramanian, Elia Gatti, Benjamin Long, and Thomas Carter. 2015. Emotions Mediated Through Mid-Air Haptics. In Proceedings of the 33rd Annual ACM Conference on Human Factors in Computing Systems - CHI '15, ACM Press, Seoul, Republic of Korea, 20532062. DOI:https://doi.org/10.1145/2702123.2702361

[54] Temitayo A. Olugbade, Aneesha Singh, Nadia Bianchi-Berthouze, Nicolai Marquardt, Min S. H. A Aung, and Amanda De C. Williams. 2019. How can affect be detected and represented in technological support for physical rehabilitation? ACM Trans. Comput.-Hum. Interact. 26, 1 (2019), Article 1, pp 1-29. DOI:https://doi.org/10.1145/3299095

[55] David Parisi. 2018. Archaeologies of Touch: Interfacing with Haptics from Electricity to Computing . University of Minnesota Press.

[56] Young-Woo Park, Kyoung-Min Baek, and Tek-Jin Nam. 2013. The roles of touch during phone conversations: long-distance couples' use of POKE in their homes. In SIGCHI Conference on Human Factors in Computing Systems, 1679-1688.

[57] Bruna Beatriz Petreca, Carmen Saito, Sharon Baurley, Douglas Atkinson, Xuemei Yu, and Nadia Bianchi-Berthouze. 2019. Radically Relational Tools: A Design Framework to Explore Materials through Embodied Processes. Int. J. Des. 13, 2 (2019), 7-20.

[58] Sara Price, Carey Jewitt, and Nikoleta Yiannoutsou. 2021. Conceptualising touch in VR. Virtual Real. (January 2021). DOI:https://doi.org/10.1007/s10055-020-00494-y

[59] Charles L. Raison, Mathew W. Hale, Lawrence E. Williams, Tor D. Wager, and Christopher A. Lowry. 2015. Somatic influences on subjective well-being and affective disorders: the convergence of thermosensory and central serotonergic systems. Front. Psychol. 5, (2015).

[60] Harry T. Reis. 1998. Gender differences in intimacy and related behaviors: Context and process. In LEA's communication series. Sex differences and similarities in communication: Critical essays 
and empirical investigations of sex and gender in interaction, D.J. Canary and K. Dindia (eds.). Lawrence Erlbaum Associates, Mahwah NJ, US, 203-231.

[61] Maria Sanchez-Vives, Bernhard Spanlang, Antonio Frisoli, Massimo Bergamasco, and Mel Slater. 2010. Virtual Hand Illusion Induced by Visuomotor Correlations. PLoS ONE 5, 4 (2010), e10381. DOI:https://doi.org/10.1371/journal.pone.0010381

[62] Je Seungwoo, Brendan Rooney, Liwei Chan, and Andrea Bianchi. 2017. TactoRing: A Skin-Drag Discrete Display. In Proceedings of the 2017 CHI Conference on Human Factors in Computing Systems, Association for Computing Machinery, New York, NY, USA, 3106-3114. DOI:https://doi.org/10.1145/3025453.3025703

[63] Michelle N. Shiota, Belinda Campos, Christopher Oveis, Matthew J. Hertenstein, Emiliana SimonThomas, and Dacher Keltner. 2017. Beyond happiness: Building a science of discrete positive emotions. Am. Psychol. 72, 7 (2017), 617-643. DOI:https://doi.org/10.1037/a0040456

[64] Marcia J Simmering, Bryan Fuller, Laura E Marler, Susie S Cox, and Rebecca J Bennett. 2013. Tactile Interaction Norms and Positive Workplace Touch. J. Manag. Issues 15, 2 (2013), 132-153.

[65] Samarth Singhal, Carman Neustaedter, Yee Loong Ooi, Alissa N. Antle, and Brendan Matkin. 2017. Flex-N-Feel: The Design and Evaluation of Emotive Gloves for Couples to Support Touch Over Distance. In Proceedings of the 2017 ACM Conference on Computer Supported Cooperative Work and Social Computing - CSCW '17, ACM Press, Portland, Oregon, USA, 98-110. DOI:https://doi.org/10.1145/2998181.2998247

[66] Jocelyn Smith and Karon MacLean. 2007. Communicating emotion through a haptic link: Design space and methodology. Int. J. Hum.-Comput. Stud. 65, 4 (April 2007), 376-387. DOI:https://doi.org/10.1016/j.ijhcs.2006.11.006

[67] Andrew A. Stanley and Katherine J. Kuchenbecker. 2011. Design of body-grounded tactile actuators for playback of human physical contact. In IEEE World Haptics Conference.

[68] Jürgen Steimle. 2016. Skin--The Next User Interface. Computer 49, 4 (April 2016), 83-87. DOI:https://doi.org/10.1109/MC.2016.93

[69] Bob Stone. 2019. Haptics for VR and AR - Where Are We ... Really? Retrieved September 18, 2019 from https://www.linkedin.com/pulse/haptics-vr-ar-where-we-really-bob-stone/. Retrieved September 18, 2019 from https://www.linkedin.com/pulse/haptics-vr-ar-where-we-really-bobstone/

[70] Katja Suhonen, Kaisa Väänänen-Vainio-Mattila, and Kalle Mäkelä. 2012. User Experiences and Expectations of Vibrotactile, Thermal and Squeeze Feedback in Interpersonal Communication. 205-214.

[71] Philipp Sykownik and Maic Masuch. 2020. The Experience of Social Touch in Multi-User Virtual Reality. In 26th ACM Symposium on Virtual Reality Software and Technology (VRST '20)., Association for Computing Machinery, New York, NY, USA, Article 30, 1-11. DOI:https://doi.org/10.1145/3385956.3418944

[72] Ana Tajadura-Jiménez, Maria Basia, Ophelia Deroy, Merle Fairhurst, Nicolai Marquardt, and Nadia Bianchi-Berthouze. As Light as your Footsteps: Altering Walking Sounds to Change Perceived Body Weight, Emotional State and Gait. In Proceedings of the 33rd Annual ACM Conference on Human Factors in Computing Systems, 2943-2952.

[73] James Keng Soon Teh, Adrian David Cheok, Yongsoon Choi, Charith Lasantha Fernando, Roshan Lalintha Peiris, and Owen Noel Newton Fernando. 2009. Huggy pajama: a parent and child hugging communication system. In Proceedings of the 8th International Conference on Interaction 
Design and Children - IDC '09, ACM Press, Como, Italy, 290. DOI:https://doi.org/10.1145/1551788.1551861

[74] Marc Teyssier, Gilles Bailly, Éric Lecolinet, and Catherine Pelachaud. 2017. Marc Teyssier, Gilles Bailly, Éric Survey and perspectives of social touch in HCI. In Proceedings of the 29th Conference on I'Interaction Homme-Machine (, Association for Computing Machinery, New York, NY, USA, 93-104. DOI:https://doi.org/10.1145/3132129.3132136

[75] Muhammad Umair, Corina Sas, and Hamza Muhammad Latif. 2019. Towards affective chronometry: Exploring smart materials and actuators for real-time representations of changes in arousal. In Proceedings of the 2019 on Designing Interactive Systems Conference, ACM, 14791494.

[76] Eugene Ungar and Kenneth J. Stroud. A New Approach to Defining Human Touch Temperature Standards. In 40th International Conference on Environmental Systems, Barcelona, Spain. DOI:https://doi.org/10.2514/6.2010-6310

[77] Rongrong Wang, Francis Quek, Deborah Tatar, Keng Soon Teh, and Adrian Cheok. 2012. Keep in touch: channel, expectation and experience. In In Proceedings of the SIGCHI Conference on Human Factors in Computing Systems (CHI '12), ACM, New York, NY, USA, 139-148. DOI:https://doi.org/10.1145/2207676.2207697

[78] Julia Werner, Reto Wettach, and Eva Hornecker. 2008. United-pulse: feeling your partner's pulse. In Proceedings of the 10th international conference on Human computer interaction with mobile devices and services - MobileHCI '08, ACM Press, Amsterdam, The Netherlands, 535. DOI:https://doi.org/10.1145/1409240.1409338

[79] Steve Yohanan and Karon E. MacLean. 2012. The Role of Affective Touch in Human-Robot Interaction: Human Intent and Expectations in Touching the Haptic Creature. Int. J. Soc. Robot. 4, 2 (April 2012), 163-180. DOI:https://doi.org/10.1007/s12369-011-0126-7

[80] Zhuoming Zhang, Jessalyn Alvina, Robin Héron, Stéphane Safin, Françoise Détienne, and Eric Lecolinet. 2021. Touch without Touching: Overcoming Social Distancing in Semi-Intimate Relationships with SansTouch. In Proceedings of the 2021 CHI Conference on Human Factors in Computing Systems., Association for Computing Machinery, New York, NY, USA, 1-13. DOI:https://doi.org/10.1145/3411764.3445612

[81] Zhuoming Zhang, Robin Héron, Eric Lecolinet, Françoise Detienne, and Stéphane Safin. 2019. VisualTouch: Enhancing Affective Touch Communication with Multi-modality Stimulation. In International Conference on Multimodal Interaction, Association for Computing Machinery, New York, NY, USA, 114-123. DOI:https://doi.org/10.1145/3340555.3353733 